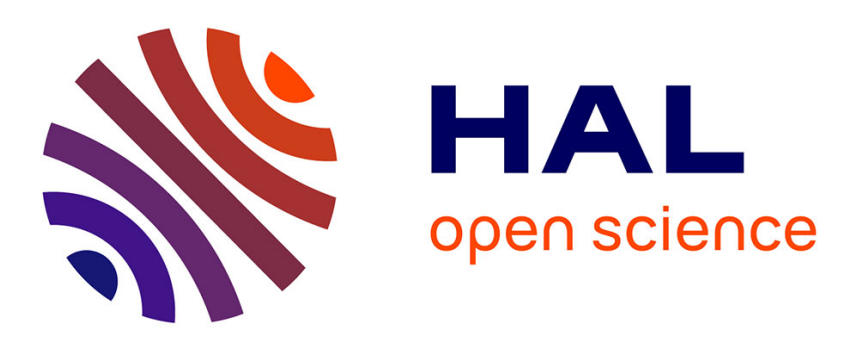

\title{
Modelling elastic and thermoelastic thick multilayered composites by a new constrained discrete layer approach
}

\author{
Monique Blanc, Maurice Touratier
}

\section{To cite this version:}

Monique Blanc, Maurice Touratier. Modelling elastic and thermoelastic thick multilayered composites by a new constrained discrete layer approach. Mechanics of Advanced Materials and Structures, 2006, 13 (1), pp.95-115. 10.1080/15376490500343915 . hal-00019248

\section{HAL Id: hal-00019248 \\ https://hal.science/hal-00019248}

Submitted on 17 Feb 2018

HAL is a multi-disciplinary open access archive for the deposit and dissemination of scientific research documents, whether they are published or not. The documents may come from teaching and research institutions in France or abroad, or from public or private research centers.
L'archive ouverte pluridisciplinaire HAL, est destinée au dépôt et à la diffusion de documents scientifiques de niveau recherche, publiés ou non, émanant des établissements d'enseignement et de recherche français ou étrangers, des laboratoires publics ou privés. 


\title{
Modelling Elastic and Thermoelastic Thick Multilayered Composites by a New Constrained Discrete Layer Approach
}

\author{
M. Blanc and M. Touratier \\ Université d'Orléans, ENSAM, Paris, France
}

\begin{abstract}
A new layer by layer/discrete layer model is presented for the linearly elastic and thermoelastic responses of multilayered composite plates. The transverse variation of the displacement field is defined in terms of a one-dimensional finite element representation, using quadratic Lagrangian interpolations. The laminate thickness is subdivided into a series of one-dimensional finite elements (i.e., thickness subdivisions) whose nodes correspond to planes of constant transverse normal coordinates in the undeformed configuration of the laminate. Each of the displacements and loads is expanded in a double Fourier series in the cartesian surface coordinates. Interface and boundary conditions are exactly verified and exploited to reduce the number of independent generalized displacements, before solving the boundary value problem from the standard variational principle for displacements. This leads to a new model, whose size $3 \mathrm{~N}$ in $3 \mathrm{D}$, is less than the classic layer by layer approach requiring $3(2 \mathrm{~N}+1)$, also in $3 \mathrm{D}$.

In addition, this model allows satisfying exactly all the interface and boundary conditions. Numerical evaluations and comparisons with exact 3D elasticity solutions confirm the efficacy of the proposed approach. Finally, the proposed modelling has been extended to the thermoelastic response of laminates and the results are compared with the exact 3D solutions. Temperature distributions required for the thermoelastic analysis are determined from the constrained discrete layer approach previously applied to heat conduction.
\end{abstract}

\section{INTRODUCTION}

Composite laminates are being increasingly used in structural applications and they require efficient analysis tools for their optimal design and reliability study. This field has been very extensively studied for several decades and is still a subject of research interest, as it is extremely difficult to find efficient modelling methods for multilayered structures with many layers and thickness zones due to the coupling between mechanics, heat transfer and moisture, and containing localized regions of complex loading or geometric or material discontinuities. Thus,

Address correspondence to M. Touratier, LMSP UMR 8106 CNRSENSAM-Université d'Orléans, 151 bd de l'Hôpital, 75013 Paris, France. E-mail: touratier@paris.ensam.fr several approaches have been developed, based mainly on either equivalent single layer or layer by layer descriptions, depending on the accuracy required for numerical simulations [1]. Unlike the equivalent single layer theories, the layer by layer theories assume separate displacement field expansions within each material layer, thus providing a kinematically correct representation of the strains in discrete layer laminates, and allowing more accurate ply-level stresses to be determined. Therefore, only layer by layer models can lead to consistent descriptions of localized effects. Extensive recent reviews on modelling multilayered plates and shells may be found in Reddy [1], Reddy and Arciniega [2], and Carrera [3-5].

In this paper, our interest concerns layer by layer descriptions along the thickness of the laminate based on quadratic Lagrangian interpolation functions. The transverse variation of the three components of the displacement field is thus defined in terms of one-dimensional finite element representations. The laminate thickness dimension is subdivided into a series of $\mathrm{M}$ one-dimensional quadratic finite elements (i.e., thickness subdivisions) at least equal to the number of layers. The proposed modelling incorporates the transverse normal strain, to be able to accurately determine interlaminar stresses by satisfying exactly all interface plus top and bottom boundary conditions from standard variational formulations, not using 3D equilibrium equations for transverse stress distribution determinations, as, for example, in Robbins and Reddy [6]. Pioneer work in layer by layer approximations such as one-dimensional finite element representation along the thickness of the laminate was published by Reddy [7], and it is termed the "layerwise" theory. Applications of the layerwise theory to piezoelectric laminates can be found in Saravanos et al. [8], Garcia Lage et al. [9], and Semedo Garção et al. [10], and for heat conduction see Blanc and Touratier [11]. Several different layer by layer approaches, not using one-dimensional finite element representation through thickness of laminates, are of course available in the literature (see Carrera [3]). A fully coupled thermoelastopiezoelectric three-dimensional solution has been presented by $\mathrm{Xu}$ et al. [12], using a mixed variational theorem for temperature, normal heat flux, displacements, normal transverse and transverse shear stresses, electric potential and normal electric displacements. Finally, exact three-dimensional solution for thermoelastic 
analysis of laminates is given in Tungikar and Rao [13], while Savoia and Reddy [14] carried out a three-dimensional thermomechanical analysis for laminated composite plates. In Matsunaga [15], comparisons between 2D single layer and 3D layerwise theories are presented for computing interlaminar stresses in laminates subjected to thermal loadings.

The objective of the present paper is to explain a new layer by layer (or discrete layer) description in which interface continuity and top and bottom boundary conditions are exploited to satisfy exactly all these conditions, and to drastically reduce model size, compared to any existing layer by layer approaches based on classic or mixed variational theorems. Thus, using quadratic Lagrangian approximation throughout thickness of laminate including $\mathrm{N}$ layers, the new approach of so called "Constrained Discrete Layer" modelling, requires, for 3D problems, choosing for example only one subdivision per layer, $3 \mathrm{~N}$ independent generalized displacements, while standard layer by layer descriptions require $3(2 \mathrm{~N}+1)$ unknowns, and $6(2 \mathrm{~N}+1)$ in a mixed modified approach if normal and shear transverse stresses are not eliminated. Note that in this last case, these stresses are quadratic too, which, of course, is not the case when using a classic variational formulation and quadratic approximation throughout the layer thickness for displacement. Specifically, the objective of this paper is to present analytic three-dimensional, doubly periodic solutions for the static response of laminated composites, consisting of a number of perfectly bonded linearly elastic/thermoelastic and fiber-reinforced layers. The solutions are periodic in the surface coordinates $\mathrm{x}_{1}$ and $\mathrm{x}_{2}$, and, as explained above, of quadratic variation along the thickness coordinate $\mathrm{x}_{3}=\mathrm{z}$ of the laminate. Periodicity for displacement and load along in-plane coordinates, allows satisfying exactly all the interface and boundary conditions within the classic displacement variational theorem. See for example Touratier [16], concerning difficulties solving the boundary value problem associated with thick lam- inates, when using a given approximate displacement field to find closed solutions. Any desired degree of displacement variation through the thickness is easily obtained by adding more one-dimensional subdivisions through the thickness. The Constrained Discrete Layer modelling is then compared with exact elasticity calculations from Pagano [17, 18]. It is confirmed that this new approach gives good results for both displacement and stress distributions through the thickness of the laminate, and allows significantly reducing the size of the problem to be solved.

Responses in thermoelasticity for a rectangular laminate have been analyzed and compared with exact three-dimensional calculations from Tungikar and Rao [13]. Once again, the present constrained discrete layer modelling gives accurate distributions for temperatures, displacements and thermal stresses through the thickness of a simply supported square sandwich plate, submitted to both thermal and mechanical loading.

\section{FORMULATION OF THE BOUNDARY VALUE PROBLEM IN LINEAR ELASTICITY}

\subsection{Expansions for Displacement Field and Traction Components Along Mid-Plane Coordinates}

A laminated plate occupying the parallelepipedic domain $\mathrm{V}$ of lateral edge $\Gamma_{\mathrm{e}}$, constituted by $\mathrm{N}$ homogeneous anisotropic layers $\mathrm{V}^{(\mathrm{i})}$ is considered, see Figure 1. The plate is referred to an orthogonal coordinate system $\Re=\left\{\mathrm{O} / \mathrm{x}_{\alpha}, \mathrm{x}_{3}=\mathrm{z}\right\}$, where the $\mathrm{x}_{\alpha}(\alpha=1,2)$ axes lie in reference plane $\mathrm{A}$ of the plate and $\mathrm{x}_{3}=\mathrm{z}$ is in the transverse direction. The top and bottom faces of the plate and the layer interfaces, located at $\mathrm{x}_{3}=\mathrm{x}_{3 \mathrm{t}}, \mathrm{x}_{3 \mathrm{~b}}$ and $\mathrm{x}_{3 \mathrm{i}}(\mathrm{i}=1, \mathrm{~N}-1)$, are denoted by $\Gamma_{\mathrm{t}}, \Gamma_{\mathrm{b}}$ and $\Gamma_{\mathrm{i}}$, respectively. The plate has combinations of homogeneous cross-ply orthotropic layers of constant thickness, $\mathrm{L}_{1}$ and $\mathrm{L}_{2}$ are the side lengths in the $\mathrm{x}_{1}$ and $\mathrm{x}_{2}$ directions and $\mathrm{h}$ is the total thickness of the plate.

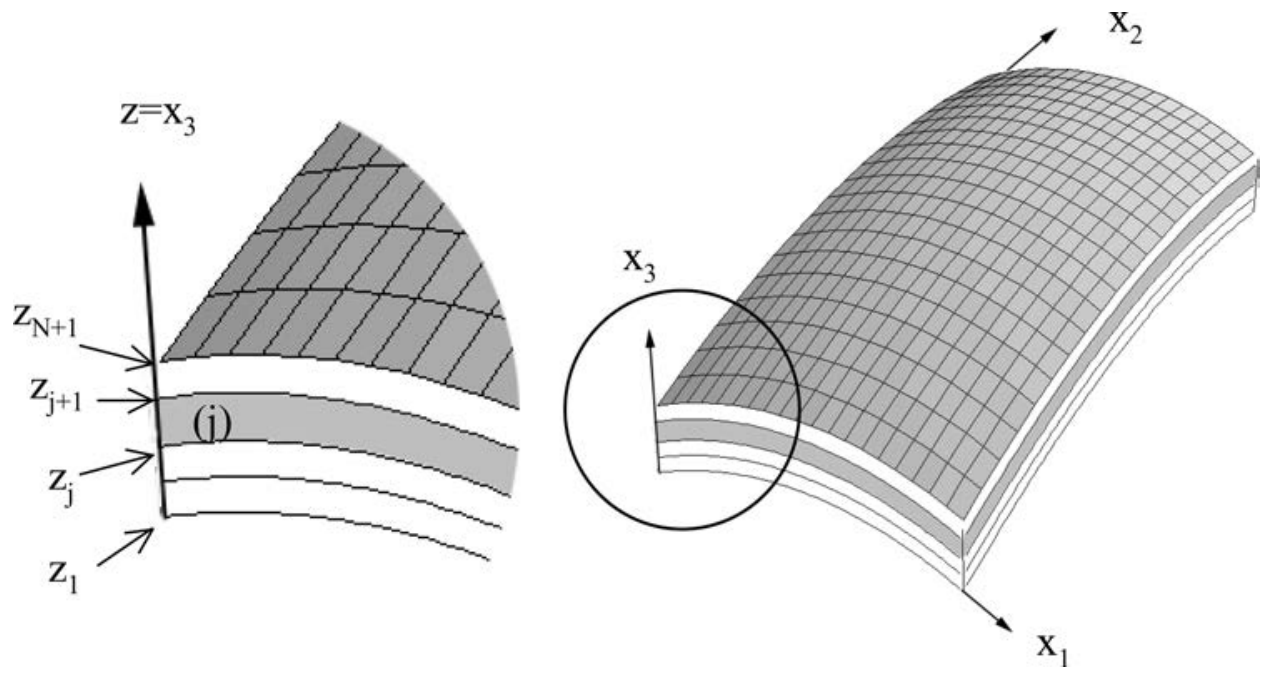

FIG. 1. The composite laminate configuration. 
The traction components $F_{i}(i=1$ to 3 ) at the top and bottom surfaces of the plate, are functions of the $x_{1}$ and $\mathrm{x}_{2}$, i.e.:

$$
\left\{\begin{array}{l}
\mathrm{F}_{\mathrm{i}}^{\mathrm{t}}=\mathrm{F}_{\mathrm{i}}^{\mathrm{t}}\left(\mathrm{x}_{1}, \mathrm{x}_{2}\right) \\
\mathrm{F}_{\mathrm{i}}^{\mathrm{b}}=\mathrm{F}_{\mathrm{i}}^{\mathrm{b}}\left(\mathrm{x}_{1}, \mathrm{x}_{2}\right)
\end{array}\right.
$$

where the superscripts $t$ and $b$ refer to the top and bottom surfaces, respectively.

For laminates consisting of cross-ply layers, each of the displacement components $u_{i}$ is expressed as the sum of products of trigonometric functions in the Cartesian surface coordinates. The trigonometric functions are chosen so that the response quantities are periodic in $\mathrm{x}_{1}$ and $\mathrm{x}_{2}$ with periods $2 \mathrm{~L}_{1}$ and $2 \mathrm{~L}_{2}$, as:

$$
\begin{gathered}
\underline{\mathrm{u}}=\sum_{\mathrm{r}=0}^{\infty} \sum_{\mathrm{s}=0}^{\infty} \underline{\underline{\mathrm{T}_{(\mathrm{rs})}}}\left(\mathrm{x}_{1}, \mathrm{x}_{2}\right) \underline{\mathrm{U}_{(\mathrm{rs})}}(\mathrm{z}) \\
\text { with } \underline{\mathrm{U}_{(\mathrm{rs})}^{\mathrm{T}}(\mathrm{z})=\left\{\mathrm{U}_{1(\mathrm{rs})}(\mathrm{z}), \mathrm{U}_{2(\mathrm{rs})}(\mathrm{z}), \mathrm{U}_{3(\mathrm{rs})}(\mathrm{z})\right\}} \\
\underline{\underline{\mathrm{T}_{(\mathrm{s})}}}=\left(\begin{array}{ccc}
\cos \mathrm{a}_{\mathrm{r}} \mathrm{x}_{1} \sin \mathrm{b}_{\mathrm{s}} \mathrm{x}_{2} & 0 & 0 \\
0 & \sin \mathrm{a}_{\mathrm{r}} \mathrm{x}_{1} \cos \mathrm{b}_{\mathrm{s}} \mathrm{x}_{2} & 0 \\
0 & 0 & \sin \mathrm{a}_{\mathrm{r}} \mathrm{x}_{1} \sin \mathrm{b}_{\mathrm{s}} \mathrm{x}_{2}
\end{array}\right)
\end{gathered}
$$

and where $\mathrm{a}_{\mathrm{r}}=\frac{\mathrm{r} \pi}{\mathrm{L}_{1}}, \mathrm{~b}_{\mathrm{s}}=\frac{\mathrm{s} \pi}{\mathrm{L}_{2}} ; \mathrm{r}$ and $\mathrm{s}$ being integers. Therefore, the following displacement conditions are satisfied by Eq. (2) as:

$$
\begin{cases}\mathrm{x}_{1}=0, \mathrm{~L}_{1} ; & \mathrm{u}_{2}=\mathrm{u}_{3}=0 \\ \mathrm{x}_{2}=0, \mathrm{~L}_{2} ; & \mathrm{u}_{1}=\mathrm{u}_{3}=0\end{cases}
$$

The traction components at the top and bottom surfaces in Eq. (1) are also expanded in double Fourier series as follows

$$
\left\{\begin{array}{l}
\underline{\mathrm{F}}^{\mathrm{b}}=\sum_{\mathrm{r}} \sum_{\mathrm{s}} \underline{\underline{\underline{\mathrm{T}}(\mathrm{rs})}} \underline{\mathrm{F}}_{\mathrm{rs}}^{\mathrm{b}} \\
\underline{\mathrm{F}}^{\mathrm{t}}=\sum_{\mathrm{r}} \sum_{\mathrm{s}} \underline{\underline{\underline{\mathrm{T}}(\mathrm{rs})}} \underline{\mathrm{F}}_{\mathrm{rs}}^{\mathrm{t}} \\
\underline{\mathrm{F}}_{(\mathrm{rs})}^{\mathrm{qT}}=\left\{\mathrm{F}_{1(\mathrm{rs})}^{\mathrm{q}} \quad \mathrm{F}_{2(\mathrm{rs})}^{\mathrm{q}} \quad \mathrm{F}_{3(\mathrm{rs})}^{\mathrm{q}}\right\} ; \quad \mathrm{q}=\mathrm{b}, \mathrm{t}
\end{array}\right.
$$

\subsection{Discrete Layer Approach Along the Thickness of the Laminate}

The laminate being subdivided into $\mathrm{N}$ discrete layers, see Figure 2, from Eq. (2) a continuous displacement field per layer is then written in the thickness direction by

$$
\left\{\begin{array}{l}
\underline{\mathrm{U}}_{(\mathrm{rs})}=\sum_{\mathrm{j}=1}^{\mathrm{N}} \chi_{\mathrm{z}_{\mathrm{j}-1}, \mathrm{z}_{\mathrm{j}}[} \underline{\mathrm{U}}_{(\mathrm{rs})}^{(\mathrm{j})} \\
\left.\chi_{\mathrm{z}_{\mathrm{j}-1}, \mathrm{z}_{\mathrm{j}}[}=1 \text { if } \mathrm{z} \in\right] \mathrm{z}_{\mathrm{j}-1}, \mathrm{z}_{\mathrm{j}}[, 0 \text { elsewhere }
\end{array}\right.
$$

Introducing the non-dimensionalized thickness coordinate $\xi_{\mathrm{i}}$ for each layer $\mathrm{V}^{(\mathrm{j})}$ as in Figure 2, the generalized displacements $\mathrm{U}_{\mathrm{i}(\mathrm{rs})}^{(\mathrm{j})}$ per layer are approximated along the thickness of the layer by quadratic Lagrange polynomia $\mathrm{l}_{\mathrm{k}}^{\mathrm{j}}$ as

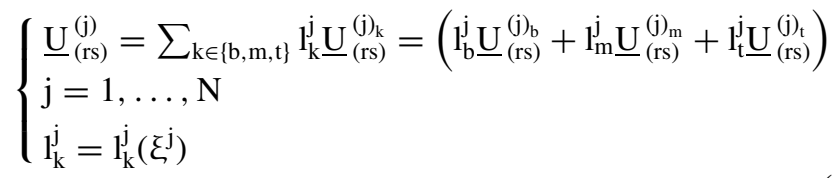

where $\mathrm{U}_{\mathrm{i}(\mathrm{rs})}^{(\mathrm{j})_{\mathrm{k}}}$ are constants and where

$$
\left\{\begin{array}{l}
-1 \leq \xi^{\mathrm{j}} \leq 1 \\
\xi^{\mathrm{j}}=\frac{\left(2 \mathrm{z}-\left(\mathrm{z}_{\mathrm{j}-1}+\mathrm{z}_{\mathrm{j}}\right)\right)}{\left(\mathrm{z}_{\mathrm{j}}-\mathrm{z}_{\mathrm{j}-1}\right)} \\
\text { b: bottom; m: medium; t: top }
\end{array}\right.
$$

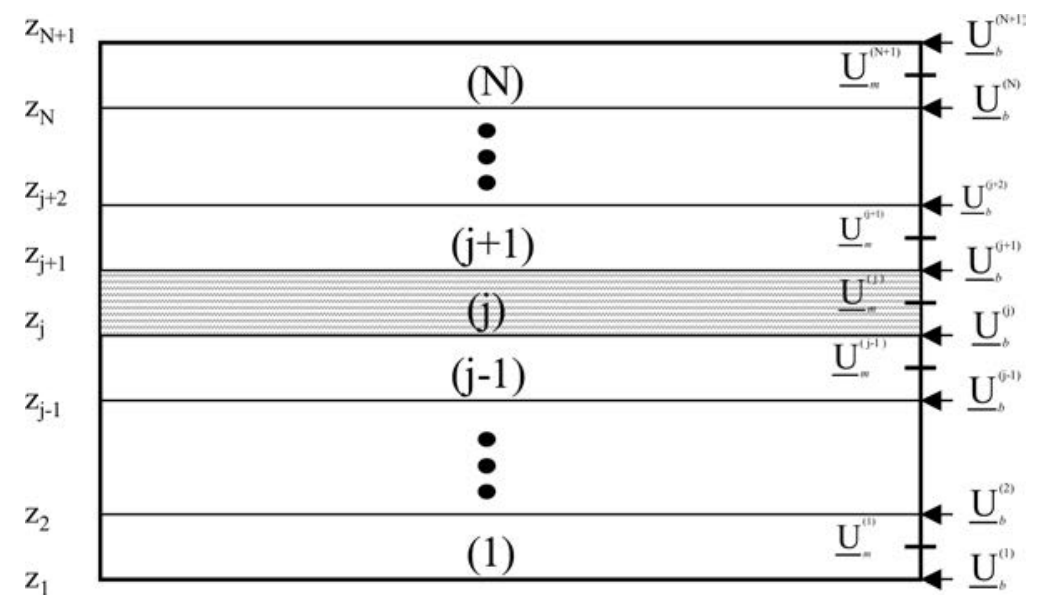

FIG. 2. Thickness subdivisions of the laminate and generalized displacements. 
It is directly deduced from the above equations that the continuity of the displacement field at the layer interfaces is then automatically satisfied, and we obtain

$$
\underline{\mathrm{U}}_{(\mathrm{rs})}^{(\mathrm{j})}=\mathrm{l}_{\mathrm{b}}^{\mathrm{j}} \underline{\mathrm{U}}_{(\mathrm{rs})}^{(\mathrm{j})_{\mathrm{b}}}+\mathrm{l}_{\mathrm{m}}^{\mathrm{j}} \underline{\mathrm{U}}_{(\mathrm{rs})}^{(\mathrm{j})_{\mathrm{m}}}+\mathrm{l}_{\mathrm{t}}^{\mathrm{j}} \underline{\mathrm{U}}_{(\mathrm{rs})}^{(\mathrm{j}+1)_{\mathrm{b}}}
$$

Thus, the displacement field at any point of the laminate is finally written from Eqs. (2), (5) and (8) as

$$
\underline{\mathrm{u}}=\sum_{\mathrm{j}=1}^{\mathrm{N}} \sum_{\mathrm{r}=0}^{\infty} \sum_{\mathrm{s}=0}^{\infty} \chi_{\mathrm{z}_{\mathrm{j}-1}, \mathrm{z}_{\mathrm{j}} \mathrm{T}} \underline{\underline{\mathrm{T}_{(\mathrm{rs})}}}\left(\mathrm{l}_{\mathrm{b}}^{\mathrm{j}} \underline{\mathrm{U}}_{(\mathrm{rs})}^{(\mathrm{j})_{\mathrm{b}}}+\mathrm{l}_{\mathrm{m}}^{\mathrm{j}} \underline{\mathrm{U}}_{(\mathrm{rs})}^{(\mathrm{j})_{\mathrm{m}}}+\mathrm{l}_{\mathrm{t}}^{\mathrm{j}} \underline{\mathrm{U}}_{(\mathrm{rs})}^{(\mathrm{j}+1)_{\mathrm{b}}}\right)
$$

\subsection{The New So-Called "Constrained Discrete Layer" Approach: Interface and Top and Bottom Conditions for Stresses; Constraints and Final Displacement Field}

The novelty of the present approach called "constrained discrete layer" is in taking into exactly account both interface continuity, and traction on the top and bottom conditions of a laminate. Hereafter, these conditions are exactly verified to reduce the number of unknowns (number of independent generalized displacements $\mathrm{U}_{\mathrm{i}(\mathrm{rs})}^{\left(\mathrm{j} \mathrm{k}_{\mathrm{k}}\right.}$ ). Denoting $\sigma_{\mathrm{ij}}^{(1)}$ the stresses per layer, the above conditions on stresses, respectively at interfaces and at bottom and top surfaces, yield

$$
\begin{aligned}
& \sigma_{3 \mathrm{i}}^{(\mathrm{j})}\left(\mathrm{x}_{1}, \mathrm{x}_{2}, \mathrm{z}_{\mathrm{j}}\right)=\sigma_{3 \mathrm{i}}^{(\mathrm{j}+1)}\left(\mathrm{x}_{1}, \mathrm{x}_{2}, \mathrm{z}_{\mathrm{j}}\right) \\
& \mathrm{j}=1, \ldots, \mathrm{N}-1 ; \mathrm{i} \in\{1,2,3\} \\
& \sigma_{3 \mathrm{i}}^{(1 \text { or } \mathrm{N})}\left(\mathrm{x}_{1}, \mathrm{x}_{2}, 0 \text { or } \mathrm{h}\right)=\delta_{\mathrm{i} 3} \mathrm{~F}_{3}^{\mathrm{b} \text { or } \mathrm{t}} \\
& \delta_{\mathrm{i} 3} \text { Kronecker's symbol }
\end{aligned}
$$

Introducing the orthotropic elastic constitutive law per $j$ th layer, one obtains the stresses per layer as following

$$
\left(\begin{array}{c}
\sigma_{11}^{(\mathrm{j})} \\
\sigma_{22}^{(\mathrm{j})} \\
\sigma_{33}^{(\mathrm{j})} \\
\sigma_{23}^{(\mathrm{j})} \\
\sigma_{31}^{(\mathrm{j})} \\
\sigma_{12}^{(\mathrm{j})}
\end{array}\right)=\left(\begin{array}{cccccc}
C_{1111}^{(\mathrm{j})} & C_{1122}^{(\mathrm{j})} & C_{1133}^{(\mathrm{j})} & 0 & 0 & 0 \\
C_{1122}^{(\mathrm{j})} & C_{2222}^{(\mathrm{j})} & C_{2233}^{(\mathrm{j})} & 0 & 0 & 0 \\
C_{1133}^{(\mathrm{j})} & C_{2233}^{(\mathrm{j})} & C_{3333}^{(\mathrm{j})} & 0 & 0 & 0 \\
0 & 0 & 0 & C_{2323}^{(\mathrm{j})} & 0 & 0 \\
0 & 0 & 0 & 0 & C_{3131}^{(\mathrm{j})} & 0 \\
0 & 0 & 0 & 0 & 0 & C_{1212}^{(\mathrm{j})}
\end{array}\right)\left(\begin{array}{c}
\mathrm{u}_{1,1}^{(\mathrm{j})} \\
\mathrm{u}_{2,2}^{(\mathrm{j})} \\
\mathrm{u}_{3,3}^{(\mathrm{j})} \\
\mathrm{u}_{2,3}^{(\mathrm{j})}+\mathrm{u}_{3,2}^{(\mathrm{j})} \\
\mathrm{u}_{1,3}^{(\mathrm{j})}+\mathrm{u}_{3,1}^{(\mathrm{j})} \\
\mathrm{u}_{1,2}^{(\mathrm{j})}+\mathrm{u}_{2,1}^{(\mathrm{j})}
\end{array}\right)
$$

where $\mathrm{C}_{\text {lnpq }}^{(\mathrm{j})}$ are the elastic constants of the material of the $j$ th-layer; $u_{i}^{(j)}$ are components per layer of the displacement field which, from Eq. (9), reduces to

$$
\underline{\mathrm{u}}_{(\mathrm{rs})}^{(\mathrm{j})}=\underline{\underline{\mathrm{T}_{(\mathrm{rs})}}}\left(\mathrm{l}_{\mathrm{b}}^{\mathrm{j}} \underline{\mathrm{U}}_{(\mathrm{rs})}^{(\mathrm{j})_{\mathrm{b}}}+\mathrm{l}_{\mathrm{m}}^{\mathrm{j}} \underline{\mathrm{U}}_{(\mathrm{rs})}^{(\mathrm{j})_{\mathrm{m}}}+\mathrm{l}_{\mathrm{t}}^{\mathrm{j}} \underline{\mathrm{U}}_{(\mathrm{rs})}^{(\mathrm{j}+1)_{\mathrm{b}}}\right)
$$

Using expressions for stresses in $j$ th-layer deduced from Eqs. (12) and (13), into Eq. (10), gives interface conditions, and bottom and top boundary conditions
- at interfaces

$$
\begin{gathered}
\underline{\hat{\mathrm{C}}}_{(\mathrm{rs}) \mathrm{i} 3}^{(\mathrm{j}) \mathrm{T}} \underline{\mathrm{U}}_{(\mathrm{rs})}^{(\mathrm{j})_{\mathrm{b}}}+\underline{\hat{\mathrm{C}}}_{(\mathrm{rs}) \mathrm{i} 3}^{(\mathrm{j}+1) \mathrm{T}} \underline{\mathrm{U}}_{(\mathrm{rs})}^{(\mathrm{j}+1)_{\mathrm{b}}}-\underline{\hat{\mathrm{C}}}_{(\mathrm{rs}) \mathrm{i} 3}^{(\mathrm{j}+2) \mathrm{T}} \underline{\mathrm{U}}_{(\mathrm{rs})}^{(\mathrm{j}+2)_{\mathrm{b}}} \\
\quad=-\underline{\hat{\mathrm{B}}}_{(\mathrm{rs}) \mathrm{i} 3}^{(\mathrm{j}) \mathrm{U}} \underline{\mathrm{U}}_{(\mathrm{rs})}^{(\mathrm{j})_{\mathrm{m}}}+\underline{\hat{\mathrm{B}}}_{(\mathrm{rs}) \mathrm{i} 3 \underline{\mathrm{U}}_{(\mathrm{rs})}^{(\mathrm{j}+1) \mathrm{T}}}^{(\mathrm{j}+1)_{\mathrm{m}}} \\
\mathrm{i}=1,2,3 ; \quad \mathrm{j}=1,2, \ldots, \mathrm{N}-1
\end{gathered}
$$

- at bottom and top surfaces

$$
\begin{gathered}
\underline{\hat{\mathrm{C}}}_{(\mathrm{rs}) \mathrm{i} 3}^{\left(\mathrm{b}_{1} \text { or } \mathrm{t}_{\mathrm{N}}\right) \mathrm{T}} \underline{\mathrm{U}}_{(\mathrm{rs})}^{(1 \text { or } \mathrm{N})_{\mathrm{b}}}+\underline{\hat{\mathrm{C}}}_{(\mathrm{rs}) \mathrm{i} 3}^{\left(\mathrm{b}_{2} \mathrm{or} \mathrm{t}_{\mathrm{N}+1}\right) \mathrm{T}} \underline{\mathrm{U}}_{(\mathrm{rs})}^{(2 \text { or } \mathrm{N}+1)_{\mathrm{b}}} \\
\quad=\delta_{\mathrm{i} 3} \mathrm{~F}_{3}^{\mathrm{b} \text { or } \mathrm{t}}-\underline{\hat{\mathrm{B}}}_{(\mathrm{rs}) \mathrm{i} 3}^{\left(\mathrm{b}_{1} \text { or } \mathrm{t}_{\mathrm{N}}\right) \mathrm{T}} \underline{\mathrm{U}}_{(\mathrm{rs})}^{(1 \text { or } \mathrm{N})_{\mathrm{m}}} \\
\mathrm{i}=1,2,3
\end{gathered}
$$

Coefficients of submatrices $\underline{\hat{C}}_{(\mathrm{rs}) \mathrm{i} 3}^{(\mathrm{l})}$ and $\underline{\hat{\mathrm{B}}}_{(\mathrm{rs}) \mathrm{i} 3}^{(\mathrm{n})}$ are given in Appendix. These Eqs. (14) and (15) allow us to eliminate all the generalized displacements $\underline{U}_{(\mathrm{rs})}^{(\mathrm{j})_{\mathrm{b}}}, \underline{\mathrm{U}}_{(\mathrm{rs})}^{(\mathrm{j}+1)_{\mathrm{b}}}$. Therefore, all the conditions expressed by Eqs. (14) and (15) can be written under the following algebraic system in $\underline{\mathrm{U}}_{(\mathrm{rs})}^{\mathrm{b}}$ :

$$
\underline{\underline{\mathrm{C}}}_{(\mathrm{rs})} \underline{\mathrm{U}}_{(\mathrm{rs})}^{\mathrm{b}}=\underline{\underline{\mathrm{B}}}_{(\mathrm{rs})} \underline{\mathrm{U}}_{(\mathrm{rs})}^{\mathrm{m}}+\underline{\mathrm{F}}_{3(\mathrm{rs})}
$$

In this last algebraic system, coefficients of matrices $\underline{\underline{\hat{C}}}(\mathrm{rs})$ and $\underline{\underline{\hat{B}}}$ (rs) are extracted from Eqs. (14) and (15). In addition, we have established:

$$
\begin{aligned}
& \underline{\mathrm{U}}_{(\mathrm{rs})}^{\mathrm{bT}}=\left\{\underline{\mathrm{U}}_{(\mathrm{rs})}^{(1)_{\mathrm{b}} \mathrm{T}} \underline{\mathrm{U}}_{(\mathrm{rs})}^{(2)_{\mathrm{b}} \mathrm{T}} \cdots \underline{\mathrm{U}}_{(\mathrm{rs})}^{(\mathrm{N}+1)_{\mathrm{b}} \mathrm{T}}\right\} \\
& \underline{\mathrm{U}}_{(\mathrm{rs})}^{\mathrm{mT}}=\left\{\underline{\mathrm{U}}_{(\mathrm{rs})}^{(1)_{\mathrm{m}}^{\mathrm{T}}} \underline{\mathrm{U}}_{(\mathrm{rs})}^{(2)_{\mathrm{m}} \mathrm{T}} \cdots \underline{\mathrm{U}}_{(\mathrm{rs})}^{(\mathrm{N})_{\mathrm{m}} \mathrm{T}}\right\} \\
& \underline{\mathrm{F}}_{3(\mathrm{rs})}^{\mathrm{T}}=\left\{00 \mathrm{~F}_{3(\mathrm{rs})}^{\mathrm{b}} 0 \cdots 000 \mathrm{~F}_{3(\mathrm{rs})}^{\mathrm{t}}\right\}
\end{aligned}
$$

Then, the system given by Eq. (16) is solved in respect to $\underline{\mathrm{U}}_{(\mathrm{rs})}^{\mathrm{b}}$. This leads to a final displacement field of the following form:

$$
\begin{aligned}
\underline{\mathrm{u}}= & \sum_{\mathrm{j}=1}^{\mathrm{N}} \sum_{\mathrm{r}=0}^{\infty} \sum_{\mathrm{s}=0}^{\infty} \chi_{\mathrm{z}_{\mathrm{j}-1}, \mathrm{z}_{\mathrm{j}} \mathrm{I}} \underline{\underline{T}}_{(\mathrm{rs})}\left(\mathrm{l}_{\mathrm{b}}^{\mathrm{j}}\left(\underline{\underline{\mathrm{C}}}_{(\mathrm{rs})}^{-1}\left(\underline{\underline{\mathrm{B}}}_{(\mathrm{rs})} \underline{\mathrm{U}}_{(\mathrm{rs})}^{\mathrm{m}}+\underline{\mathrm{F}}_{3(\mathrm{rs})}\right)\right)_{\mathrm{j}_{\mathrm{row}}^{\mathrm{th}}}\right. \\
& \left.+\mathrm{l}_{\mathrm{m}}^{\mathrm{j}} \underline{\mathrm{U}}_{(\mathrm{rs})}^{(\mathrm{j})_{\mathrm{m}}}+\mathrm{l}_{\mathrm{t}}^{\mathrm{j}}\left(\underline{\underline{\hat{C}}}_{(\mathrm{rs})}^{-1}\left(\underline{\underline{\hat{B}}}_{(\mathrm{rs})} \underline{\mathrm{U}}_{(\mathrm{rs})}^{\mathrm{m}}+\underline{\mathrm{F}}_{3(\mathrm{rs})}\right)\right)_{\mathrm{j}+1_{\mathrm{row}}^{\mathrm{th}}}\right)
\end{aligned}
$$

Remark. At this stage, and adopting quadratic polynomial approximations for displacements in each layer, it is important to observe that this constrained discrete layer model based upon Eq. (18), leads only to $3 \mathrm{~N}$ generalized displacements to be determined for three-dimensional laminates having $\mathrm{N}$ layers. In comparison, the standard discrete layer theory (based on displacement variational theorem) requires $3(2 \mathrm{~N}+1)$ unknowns, while the discrete layer modelling based on modified Reissner's mixed variational theorem involves $6(2 \mathrm{~N}+1)$ unknowns, but transverse (both normal and shear) stresses are quadratic [19]. It is of course possible to improve accuracy either by discretizing layers in sub-layers, keeping the same quadratic approximation for each, or employing higher order polynomia along the thickness. 


\subsection{Governing Equations}

The equilibrium equations and natural boundary conditions on the edge of the laminate are derived in classic manner via the standard displacement variational theorem as:

$$
\begin{aligned}
0= & \int_{\mathrm{V}}\left(\mathrm{C}_{\mathrm{ijk} k l} \frac{\partial^{2} \mathrm{u}_{\mathrm{l}}}{\partial \mathrm{x}_{\mathrm{j}} \partial \mathrm{x}_{\mathrm{k}}}+\left(\mathrm{f}_{\mathrm{i}}=0\right)\right) \delta \mathrm{u}_{\mathrm{i}}+\int_{\mathrm{V}}\left(\mathrm{F}_{\mathrm{i}}^{\mathrm{e}}-\sigma_{\mathrm{ij}} \mathrm{n}_{\mathrm{j}}\right) \delta \mathrm{u}_{\mathrm{i}} \\
& \forall \delta \mathrm{u}_{\mathrm{i}} \text { in } \mathrm{V} \text {, and } \forall \delta \mathrm{u}_{\mathrm{i}} \text { on } \Gamma_{\mathrm{e}}
\end{aligned}
$$

where $\mathrm{u}_{l}$ are components of $\underline{\mathrm{u}}$ in Eq.(18), $\mathrm{F}_{\mathrm{i}}^{e}$ are components of prescribed traction on the lateral edge $\Gamma_{\mathrm{e}}$ of $\mathrm{V}, \sigma_{\mathrm{ij}}$ are stresses computed from Eq. (12) in each layer, $n_{j}$ are components of the unitary normal outward to the edge $\Gamma_{\mathrm{e}}, \delta \mathrm{u}_{\mathrm{i}}$ is the variation operator (differential operator) of $u_{i}$. Developing Eq. (19) for each pair (r, s) of harmonics in Eq. (18), and performing integration throughout the thickness of the laminate, involves solving a linear algebraic system having $3 \mathrm{~N}$ unknowns $\mathrm{U}_{\mathrm{i}(\mathrm{rs})}^{\mathrm{m}}$. Corresponding symbolic calculations are carried out using the Mathematica system [20].

\section{EXTENSION TO THE THERMOELASTIC RESPONSE OF LAMINATES}

The above formulation of the boundary value problem is now extended to thermoelastic analyses from the constrained discrete layer approach. The described method for linearly elastic composite laminates is modified as follows to reach corresponding linearly thermoelastic responses:

Step- $i$ : Start by expanding temperature $\mathrm{T}\left(\mathrm{x}_{1}, \mathrm{x}_{2}, \mathrm{z}\right)$ as the component $\mathrm{u}_{3}$ in Eq. (2), i.e.: $\mathrm{T}=\Sigma_{\mathrm{r} \geq 0} \Sigma_{\mathrm{s} \geq 0} \sin \mathrm{a}_{\mathrm{r}} \mathrm{x}_{1} \operatorname{sinb}_{\mathrm{s}} \mathrm{x}_{2}$ $\mathrm{T}_{\text {(rs) }}(\mathrm{z})$. Then, pursue this by exchanging $\mathrm{u}_{3}$ with $\mathrm{T}$ until satisfying Eq. (9). Replacing Eq. (12) by Fourier's law available for heat conduction, and inserting it in interface and top and bottom conditions for normal heat flux similarly to Eqs. (10) and (11), we deduce the final temperature field in the following form:

$$
\begin{aligned}
\mathrm{T}\left(\mathrm{x}_{1}, \mathrm{x}_{2}, \mathrm{z}\right)= & \Sigma_{\mathrm{j}=1}^{\mathrm{N}} \Sigma_{\mathrm{r}=0}^{\infty} \Sigma_{\mathrm{s}=0}^{\infty} \chi_{] \mathrm{zj}-1, \mathrm{zj}[} \sin \mathrm{a}_{\mathrm{r}} \mathrm{x}_{1} \sin \mathrm{b}_{\mathrm{s}} \mathrm{x}_{2} \\
& \times\left\{\Sigma_{\mathrm{i}=1}^{N}\left[L_{\mathrm{m}}^{(\mathrm{i})}\left(\xi^{\mathrm{j}}, \kappa^{(1)}, \ldots \mathrm{\kappa}^{(\mathrm{N})}\right) \mathrm{T}_{(\mathrm{rs})}^{(\mathrm{i}) \mathrm{m}}\right]\right. \\
& +\left(\mathrm{L}_{\mathrm{b}}^{(1)}\left(\xi^{\mathrm{j}}, \kappa^{(1)}, \ldots \kappa^{(\mathrm{N})}\right) \mathrm{T}_{(\mathrm{rs})}^{(1) \mathrm{b}}\right. \\
& +\left(\mathrm{L}_{\mathrm{b}}^{(\mathrm{N}+1)}\left(\xi^{\mathrm{j}}, \kappa^{(1)}, \ldots \kappa^{(\mathrm{N})}\right) \mathrm{T}_{(\mathrm{rs})}^{(\mathrm{N}+1) \mathrm{b}}\right\}
\end{aligned}
$$

where coefficients $\mathrm{L}_{\mathrm{k}}^{(n)}$ depend on Lagrange polynomial, and also, both on their first derivative and on $\mathrm{K}^{(\mathrm{j})}=\mathrm{k}_{3}^{(\mathrm{j})} /\left(\mathrm{z}_{\mathrm{j}+1}-\mathrm{z}_{\mathrm{j}}\right), \mathrm{k}_{3}^{(\mathrm{j})}$ being thermal conductivities in the z-direction for an orthotropic material. In fact, coefficients $\mathrm{L}_{\mathrm{k}}^{(\mathrm{n})}$ are nothing else than quadratic B-splines.

Step-ii: Solve the heat conduction boundary value problem by using the constrained discrete layer modelling as described above in elasticity (Section 2), or from [11]. In any case, the appropriated classic variational form to be used is expressed as:

$$
\begin{aligned}
\forall \delta \mathrm{T} \text { such that } \delta \mathrm{T} & =0 \text { on } \Gamma_{\mathrm{T}}, \forall \tau: \\
\int_{0}^{\tau} \int_{\mathrm{V}} \rho \mathrm{C}_{\mathrm{V}} \mathrm{T}_{, \mathrm{t}} \delta \mathrm{TdVdt}= & \int_{0}^{\tau} \int_{\mathrm{V}} \mathrm{q}_{\mathrm{i}} \delta \mathrm{T}_{, \mathrm{i}} \mathrm{dV} \mathrm{dt}+\int_{0}^{\tau} \int_{\mathrm{V}} \rho \mathrm{w} \delta \mathrm{TdVdt} \\
& +\int_{0}^{\tau} \int_{\Gamma_{\mathrm{Q}}}\left(\mathrm{Q}_{\Gamma}+\mathrm{q} \cdot \mathrm{n}\right) \delta \mathrm{T}_{\mathrm{d} \Gamma \mathrm{dt}}
\end{aligned}
$$

where $\mathrm{Q}_{\Gamma}$ is the heat quantity prescribed (natural boundary conditions) on the part $\Gamma_{\mathrm{Q}}$ of the boundary surface $\Gamma=\Gamma_{\mathrm{t}} \cup \Gamma_{\mathrm{b}} \cup \Gamma_{\mathrm{e}}$ of the volume $\mathrm{V}$ of the laminate, $\mathrm{q}$ is the heat flux, $\mathrm{n}$ the unit normal outward from the boundary surface $\Gamma, C_{v}$ is the specific heat at constant volume, $\rho$ is the mass density, $\rho w$ is an internal source of heat, and $\delta \mathrm{T}$ is the variation of the temperature $\mathrm{T}$, at any specific time $t \in[0, \tau]$. Finally, $\Gamma_{\mathrm{T}}$ is the complementary part of $\Gamma_{\mathrm{Q}}$, where temperatures are prescribed (essential boundary conditions). The solution of the heat problem is therefore deduced from Eq. (19), by incorporating Eq. (20).

Step-iii: Modify the constitutive law Eq. (12) by superimposing the standard thermal contribution in stresses for an orthotropic behaviour. This requires adding the following vector to the second member of Eq. (12):

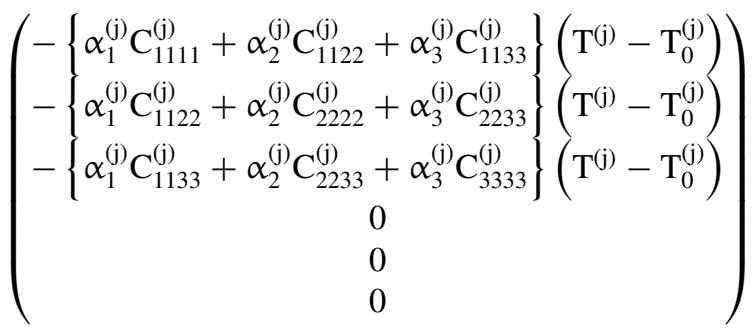

where $\mathrm{T}^{(\mathrm{j})}\left(\mathrm{x}_{1}, \mathrm{x}_{2}, \mathrm{z}\right)$ is the temperature in $j$ th layer computed at the above iith-step, $\mathrm{T}_{0}^{(\mathrm{j})}$ is the reference temperature for the $j$ th layer, while $\alpha_{\mathrm{i}}^{(\mathrm{j})}$ are coefficients of thermal expansion in the $j$ th layer;

Step-iv: Interface, and bottom and top surfaces conditions, respectively given by Eqs. (14) and (15), must incorporate the thermal contribution into stresses by adding the following terms to the second member of these equations:

*to be added to Eq. (14): $\delta_{\mathrm{i} 3}\left(\hat{\mathrm{A}}_{(\mathrm{rs}) \mathrm{i3}}^{(\mathrm{j})}-\hat{\mathrm{A}}_{(\mathrm{rs}) \mathrm{i3}}^{(\mathrm{j}+1)}\right)$, at $\mathrm{z}=\mathrm{zj}$
$\quad$ to be added to Eq. $(15): \delta_{\mathrm{i} 3} \hat{\mathrm{A}}_{(\mathrm{rs}) \mathrm{i} 3}^{(\mathrm{b} 1 \text { or tN) }}$, at $\mathrm{z}=\mathrm{z}_{1}$ or $\mathrm{z}_{\mathrm{N}}$

where coefficients $\hat{\mathrm{A}}_{(\mathrm{rs}) \mathrm{i3}}^{(\mathrm{k})}$ are expressed as:

$$
\begin{aligned}
& \hat{\mathrm{A}}_{(\mathrm{rs}) \mathrm{i3}}^{(\mathrm{k})}= \Sigma_{\mathrm{p}=1}^{3} \alpha_{\mathrm{p}}^{(\mathrm{k})} \mathrm{C}_{\mathrm{pp} 33}^{(\mathrm{k})}\left(\mathrm{T}_{(\mathrm{rs})}^{(\mathrm{k})}-\mathrm{T}_{0(\mathrm{rs})}^{(\mathrm{k})}\right) ; \\
& \mathrm{k} \in\left\{\mathrm{j}, \mathrm{j}+1, \mathrm{~b}_{1} \text { or } \mathrm{t}_{\mathrm{N}}\right\}
\end{aligned}
$$

while temperatures per layer $\mathrm{T}_{(\mathrm{rs})}^{(\mathrm{k})}$ being computed from Eqs. (20)-(21); and $\delta_{\mathrm{i} 3}$ is Kronecker's symbol;

Step-v: This results in a new vector $\mathrm{F}_{3(\mathrm{rs})}$ in Eq. (16); 
Step-vi: The final displacement field for linearly thermoelastic responses is then deduced from Eq. (18), using the new expression of $\mathrm{F}_{3(\mathrm{rs})}$ obtained at the preceding vth-step;

Step-vii: Finally, corresponding equilibrium equations and natural boundary conditions are still computed from Eq. (19).

\section{NUMERICAL STUDIES}

To assess the accuracy of the present model, the following problems for which an exact three-dimensional solution exists (which has been implemented here) from Pagano [17, 18], have been examined: first, the cylindrical bending of a simply supported plate and, second, the bending of a simply supported rectangular plate, being submitted respectively to single and double sinusoidal loading at the top of the plate. Hence, in Eqs. (2) and (4), integers $\mathrm{r}$ and $\mathrm{s}$ are kept as $\mathrm{r}=\mathrm{s}=1$; and then, simply supported conditions verify Eq. (3); while in Eq. (4) we retain $\mathrm{F}_{\mathrm{i}(11)}^{\mathrm{b}}=0, \mathrm{i}=1,2,3$, and $\mathrm{F}_{1(11)}^{\mathrm{t}}=\mathrm{F}_{2(11)}^{\mathrm{t}}=0, \mathrm{~F}_{3(11)}^{\mathrm{t}}=$ ( $\mathrm{p} \sin \left(\pi \mathrm{x}_{1} / \mathrm{L}_{1}\right) \sin \left(\pi \mathrm{x}_{2} / \mathrm{L}_{2}\right)$ for rectangular and square plates; and $\mathrm{p} \sin \left(\pi \mathrm{x}_{1} / \mathrm{L}_{1}\right)$ in cylindrical bending. We also present results for a square sandwich plate (Problem 3), and for the cylindrical bending of a bi-layer laminate (Problem 4). Finally, a thermoelastic analysis is produced for a bi-layer submitted to both thermal and mechanical loadings (cylindrical bending for Problem 5 and three-dimensional plate in Problem 6). A comparison with exact calculations is also given.

Otherwise, linearly elastic material properties are those given in Pagano [17], and are:

$$
\begin{aligned}
\mathrm{E}_{\mathrm{L}} / \mathrm{E}_{\mathrm{T}} & =25 ; \quad \mathrm{G}_{\mathrm{LT}} / \mathrm{E}_{\mathrm{T}}=0.5 ; \quad \mathrm{G}_{\mathrm{TT}} / \mathrm{E}_{\mathrm{T}}=0.2 ; \\
v_{\mathrm{LT}} & =v_{\mathrm{TT}}=0.25 ; \quad \mathrm{E}_{\mathrm{T}}=6.909 \mathrm{GPa}
\end{aligned}
$$

where $\mathrm{L}$ and $\mathrm{T}$ are the parallel and normal directions to the fibres, E is Young's modulus, G is the shear modulus, and $v$ is Poisson's ratio.

All the symbolic and numerical computations for both our new model and the exact solutions were performed by using the Mathematica system [20].

\subsection{Problem 1. Cylindrical Bending of a Simply Supported Three-Layer $90^{\circ} / 0^{\circ} / 90^{\circ}$ Symmetric Laminate under a Sinusoidal Load}

Results solving Eq. (19) are reported in Tables 1 and 2 for two thickness ratios (4 and 10), under the following dimensionalized form [17]:

$$
\left\{\begin{array}{l}
\mathrm{S}=\frac{\mathrm{L}_{1}}{\mathrm{~h}} \overline{\mathrm{Z}}=\frac{\mathrm{z}}{\mathrm{h}} \\
\overline{\mathrm{u}}_{1}=\frac{\mathrm{E}_{\mathrm{T}} \mathrm{u}_{1}(0, \mathrm{z})}{\mathrm{ph}} \overline{\mathrm{u}_{3}}=\frac{100 \mathrm{E}_{\mathrm{T}} \mathrm{u}_{3}\left(\frac{\mathrm{L}_{1}}{2}, \mathrm{z}\right)}{\mathrm{phS}^{4}} \\
\left(\bar{\sigma}_{11}, \bar{\sigma}_{33}, \bar{\sigma}_{13}\right)=\frac{1}{\mathrm{p}}\left(\sigma_{11}\left(\frac{\mathrm{L}_{1}}{2}, \mathrm{z}\right), \sigma_{33}\left(\frac{\mathrm{L}_{1}}{2}, \mathrm{z}\right), \sigma_{13}(0, \mathrm{z})\right)
\end{array}\right.
$$

The layers have equal thickness, the fibers are oriented along the $\mathrm{x}_{2}$-direction for the outer layers $\left(90^{\circ}\right)$, and along the

\section{TABLE 1}

Convergence of the CDLn model with respect to the number $\mathrm{n}=1,2,3$ of subdivisions in each layer. Calculations are extracted from Eq. (26). Problem 1: $\mathrm{S}=4$; cylindrical bending of a three-layer laminate

\begin{tabular}{lrrrr}
\hline & Elasticity & CDL1 & CDL2 & CDL3 \\
\hline$\overline{\mathrm{u}}_{1}(0)$ & 0,9212 & 1,0010 & 0,9339 & 0,9259 \\
$\overline{\mathrm{u}}_{1}(1 / 3)$ & $-0,2018$ & $-0,3086$ & $-0,2054$ & $-0,2039$ \\
$\overline{\mathrm{u}}_{1}(2 / 3)$ & 0,2509 & 0,3621 & 0,2547 & 0,2531 \\
$\overline{\mathrm{u}}_{1}(1)$ & $-0,9457$ & $-1,0332$ & $-0,9594$ & $-0,9508$ \\
$\overline{\mathrm{u}}_{3}(1 / 2)$ & 2,8901 & 2,7380 & 2,8860 & 2,8893 \\
$\bar{\sigma}_{11}(0)$ & $-18,087$ & $-19,655$ & $-18,336$ & $-18,180$ \\
$\bar{\sigma}_{11}(1 / 3)$ & 4,0400 & 6,1219 & 4,1119 & 4,0806 \\
$\bar{\sigma}_{11}(2 / 3)$ & $-4,7555$ & $-6,9234$ & $-4,8316$ & $-4,7984$ \\
$\bar{\sigma}_{11}(1)$ & 18,819 & 20,536 & 19,087 & 18,919 \\
$\bar{\sigma}_{13}(1 / 2)$ & 1,4319 & 1,5034 & 1,4435 & 1,4289 \\
\hline
\end{tabular}

$\mathrm{x}_{1}$-direction for the inner layer $\left(0^{\circ}\right)$. In Tables 1 and 2, CDLn means with "Constrained Discrete Layer" using n sub-layers for each plate's layer (see Ray and Reddy [21, 22] for constrained layer damping). We show in Figures 3 and 4, corresponding thickness distributions for displacements and stresses, using $\mathrm{n}=3$ subdivisions per layer. These are compared with the exact solution from Pagano, and a good agreement can be observed on these thickness distributions, satisfying exactly all the interface and boundary conditions.

Tables 1 and 2 show that convergence with respect to the number $\mathrm{n}$ of sub-layers for CDLn modelling is very fast between CDL1 (only one subdivision per layer) and CDL2 (two subdivisions per layer), towards exact calculations. It appears that 3 subdivisions in each layer may suffice to reach exact values at studied points in these tables.

\section{TABLE 2}

Convergence of the CDLn model with respect to the number $\mathrm{n}=1,2,3$ of subdivisions in each layer. Calculations are extracted from Eq. (26). Problem 1: $\mathrm{S}=10$; cylindrical bending of a three-layer laminate

\begin{tabular}{lrrrr}
\hline & Elasticity & CDL1 & CDL2 & CDL3 \\
\hline$\overline{\mathrm{u}}_{1}(0)$ & 9,37 & 9,49 & 9,39 & 9,38 \\
$\overline{\mathrm{u}}_{1}(1 / 3)$ & 1,389 & 1,240 & 1,382 & 1,386 \\
$\overline{\mathrm{u}}_{1}(2 / 3)$ & $-1,326$ & $-1,178$ & $-1,320$ & $-1,324$ \\
$\overline{\mathrm{u}}_{1}(1)$ & $-9,35$ & $-9,46$ & $-9,36$ & $-9,35$ \\
$\overline{\mathrm{u}}_{3}(1 / 2)$ & 0,933 & 0,929 & 0,933 & 0,933 \\
$\bar{\sigma}_{11}(0)$ & $-73,61$ & $-74,52$ & $-73,71$ & $-73,65$ \\
$\bar{\sigma}_{11}(1 / 3)$ & $-10,84$ & $-9,69$ & $-10,79$ & $-10,82$ \\
$\bar{\sigma}_{11}(2 / 3)$ & 10,60 & 9,45 & 10,55 & 10,58 \\
$\bar{\sigma}_{11}(1)$ & 73,66 & 74,57 & 73,76 & 73,69 \\
$\bar{\sigma}_{13}(1 / 2)$ & 4,239 & 4,386 & 4,245 & 4,235 \\
\hline
\end{tabular}




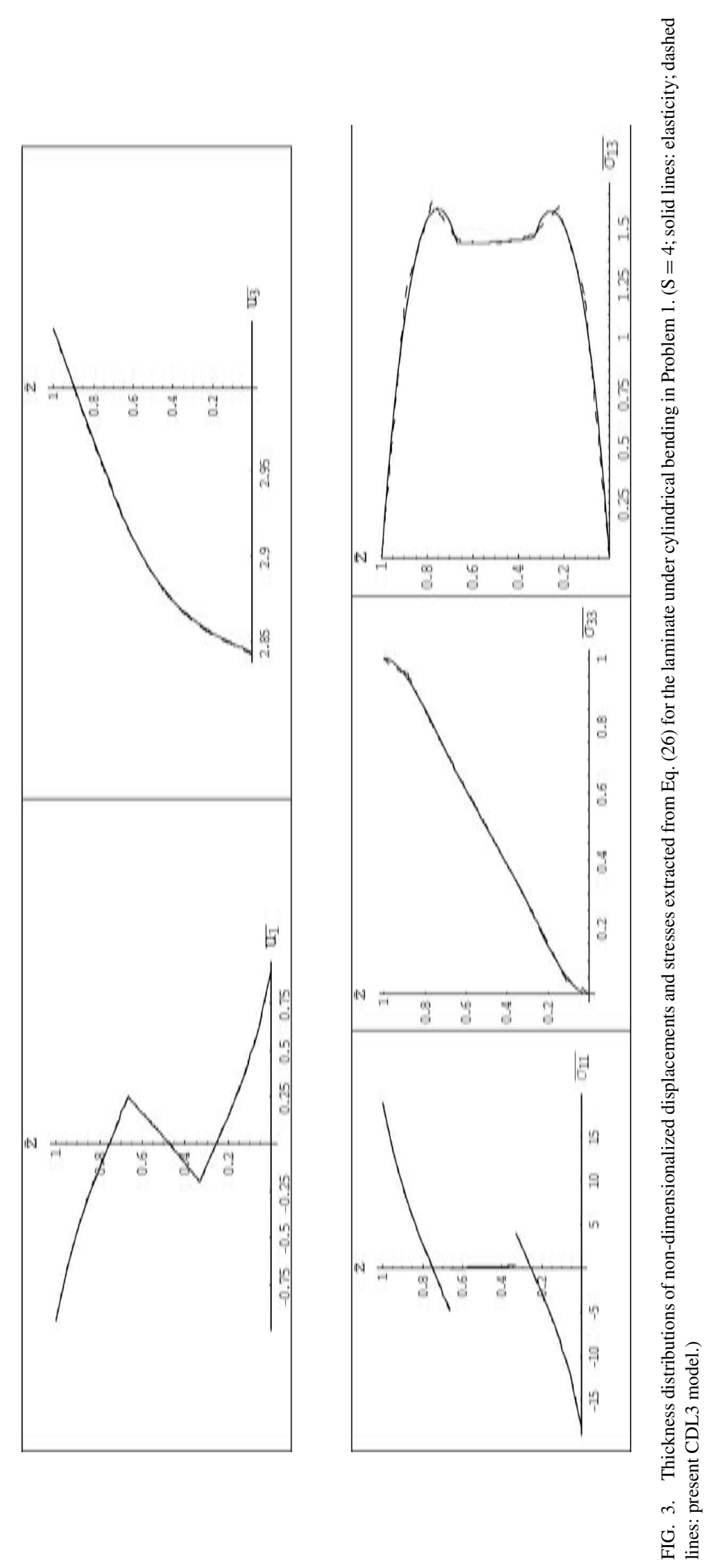




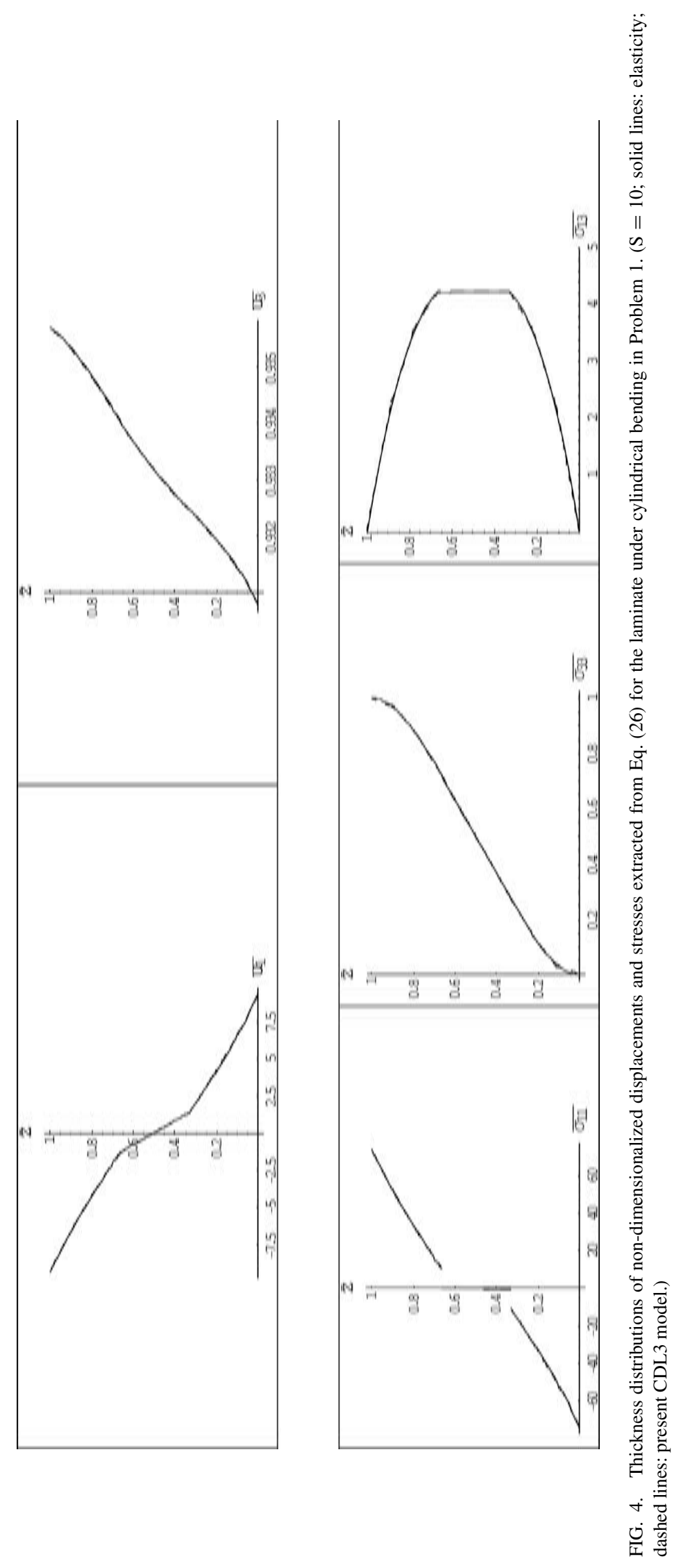




\subsection{Problem 2. Simply Supported Laminated $0^{\circ} / 90^{\circ} / 0^{\circ}$ Symmetric Rectangular Plate under Doubly Sinusoidal Load}

Material data are same as those given for Problem 1 [18], while geometric data are such that $\mathrm{L}_{2}=3 \mathrm{~L}_{1}$. Two thickness ratios are again considered for thick laminates: 4 and 10 . The layers have equal thickness, with fibers in the outer layers oriented in the $\mathrm{x}_{1}$-direction $\left(0^{\circ}\right)$ and those in the inner layer oriented in the $\mathrm{x}_{2}$-direction $\left(90^{\circ}\right)$. The plate is subjected to the doubly sinusoïdal distribution transverse loading expressed above. Tables 3 and 4 present non-dimensionalized displacements and stresses such as:

$\left\{\begin{array}{l}\mathrm{S}=\frac{\mathrm{L}_{1}}{\mathrm{~h}} \quad \overline{\mathrm{z}}=\frac{\mathrm{z}}{\mathrm{h}} \\ \overline{\mathrm{u}}_{1}=\frac{\mathrm{E}_{\mathrm{T}}\left(0, \frac{\mathrm{L}_{2}}{2}, \mathrm{z}\right)}{\mathrm{ph}^{3}} \overline{\mathrm{u}}_{2}=\frac{\mathrm{E}_{\mathrm{T}}\left(\frac{\mathrm{L}_{1}}{2}, 0, \mathrm{z}\right)}{\mathrm{phS}^{3}} \overline{\mathrm{u}}_{3}=\frac{100 \mathrm{E}_{\mathrm{T}} \mathrm{u}_{3}\left(\frac{\mathrm{L}_{1}}{2}, \frac{\mathrm{L}_{2}}{2}, \mathrm{z}\right)}{\mathrm{phS}^{4}} \\ \left(\bar{\sigma}_{11}, \bar{\sigma}_{22}, \bar{\sigma}_{12}\right)=\frac{1}{\mathrm{pS}^{2}}\left(\sigma_{11}\left(\frac{\mathrm{L}_{1}}{2}, \frac{\mathrm{L}_{2}}{2}, \mathrm{z}\right), \sigma_{22}\left(\frac{\mathrm{L}_{1}}{2}, \frac{\mathrm{L}_{2}}{2}, \mathrm{z}\right), \sigma_{12}(0,0, \mathrm{z})\right) \\ \left(\bar{\sigma}_{13}, \bar{\sigma}_{23}\right)=\frac{1}{\mathrm{pS}}\left(\sigma_{13}\left(0, \frac{\mathrm{L}_{2}}{2}, \mathrm{z}\right), \sigma_{23}\left(\frac{\mathrm{L}_{1}}{2}, 0, \mathrm{z}\right)\right) \bar{\sigma}_{33}=\frac{1}{\mathrm{p}} \sigma_{33}\left(\frac{\mathrm{L}_{1}}{2}, \frac{\mathrm{L}_{2}}{2}, \mathrm{z}\right)\end{array}\right.$

Results are also presented in Figures 5 and 6 for two thickness ratios (4 and 10). These three-dimensional computations show

TABLE 3

Convergence of the CDLn model with respect to the number $\mathrm{n}=1,2,3$ of subdivisions in each layer. Calculations are extracted from Eq. (27). Problem 2: $S=4$; sandwich rectangular plate $\mathrm{L}_{2} / \mathrm{L}_{1}=3$

\begin{tabular}{lrrrr}
\hline & Elasticity & CDL1 & CDL2 & CDL3 \\
\hline$\overline{\mathrm{u}}_{1}(0)$ & 0,0139 & 0,0152 & 0,0141 & 0,0140 \\
$\overline{\mathrm{u}}_{1}(1 / 3)$ & $-0,0031$ & $-0,0048$ & $-0,0032$ & $-0,0032$ \\
$\overline{\mathrm{u}}_{1}(2 / 3)$ & 0,0039 & 0,0056 & 0,0040 & 0,0040 \\
$\overline{\mathrm{u}}_{1}(1)$ & $-0,0142$ & $-0,0156$ & $-0,0145$ & $-0,0143$ \\
$\overline{\mathrm{u}}_{2}(0)$ & 0,0132 & 0,0126 & 0,0132 & 0,0132 \\
$\overline{\mathrm{u}}_{2}(1 / 3)$ & 0,0049 & 0,0047 & 0,0049 & 0,0049 \\
$\overline{\mathrm{u}}_{2}(2 / 3)$ & $-0,0037$ & $-0,0036$ & $-0,0037$ & $-0,0038$ \\
$\overline{\mathrm{u}}_{2}(1)$ & $-0,0124$ & $-0,0117$ & $-0,0124$ & $-0,0124$ \\
$\overline{\mathrm{u}}_{3}(1 / 2)$ & 2,821 & 2,675 & 2,817 & 2,820 \\
$\bar{\sigma}_{11}(0)$ & $-1,099$ & $-1,197$ & $-1,115$ & $-1,105$ \\
$\bar{\sigma}_{11}(1 / 3)$ & 0,252 & 0,379 & 0,256 & 0,254 \\
$\bar{\sigma}_{11}(2 / 3)$ & $-0,294$ & $-0,427$ & $-0,299$ & $-0,297$ \\
$\bar{\sigma}_{11}(1)$ & 1,144 & 1,251 & 1,161 & 1,150 \\
$\bar{\sigma}_{22}(0)$ & $-0,0248$ & $-0,0252$ & $-0,0250$ & $-0,0249$ \\
$\bar{\sigma}_{22}(1 / 3)$ & $-0,1193$ & $-0,1147$ & $-0,1191$ & $-0,1193$ \\
$\bar{\sigma}_{22}(2 / 3)$ & 0,1088 & 0,1041 & 0,1086 & 0,1088 \\
$\bar{\sigma}_{22}(1)$ & 0,0400 & 0,0404 & 0,0402 & 0,0401 \\
$\bar{\sigma}_{23}(1 / 2)$ & 0,0334 & 0,0257 & 0,0358 & 0,0330 \\
$\bar{\sigma}_{13}(1 / 2)$ & 0,3511 & 0,5444 & 0,3477 & 0,3503 \\
$\bar{\sigma}_{12}(0)$ & 0,0281 & 0,0277 & 0,0282 & 0,0281 \\
$\bar{\sigma}_{12}(1 / 3)$ & 0,0060 & 0,0049 & 0,0060 & 0,0060 \\
$\bar{\sigma}_{12}(2 / 3)$ & $-0,0038$ & $-0,0027$ & $-0,0038$ & $-0,0038$ \\
$\bar{\sigma}_{12}(1)$ & $-0,0269$ & $-0,0437$ & $-0,0270$ & $-0,0269$ \\
\hline & & & &
\end{tabular}

TABLE 4

Convergence of the CDLn model with respect to the number $\mathrm{n}=1,2,3$ of subdivisions in each layer. Calculations are extracted from Eq. (27). Problem 2: $\mathrm{S}=10$; sandwich rectangular plate $\mathrm{L}_{2} / \mathrm{L}_{1}=3$

\begin{tabular}{lrrrr}
\hline & Elasticity & \multicolumn{1}{c}{ CDL1 } & \multicolumn{1}{c}{ CDL2 } & \multicolumn{1}{c}{ CDL3 } \\
\hline$\overline{\mathrm{u}}_{1}(0)$ & 0,00920 & 0,00931 & 0,00921 & 0,00920 \\
$\overline{\mathrm{u}}_{1}(1 / 3)$ & 0,00135 & 0,00120 & 0,00134 & 0,00135 \\
$\overline{\mathrm{u}}_{1}(2 / 3)$ & $-0,00128$ & $-0,00113$ & $-0,00128$ & $-0,00128$ \\
$\overline{\mathrm{u}}_{1}(1)$ & $-0,00917$ & $-0,00928$ & $-0,00918$ & $-0,00917$ \\
$\overline{\mathrm{u}}_{2}(0)$ & 0,00475 & 0,00473 & 0,00475 & 0,00475 \\
$\overline{\mathrm{u}}_{2}(1 / 3)$ & 0,00165 & 0,00165 & 0,00165 & 0,00165 \\
$\overline{\mathrm{u}}_{2}(2 / 3)$ & $-0,00147$ & $-0,00146$ & $-0,00147$ & $-0,00147$ \\
$\overline{\mathrm{u}}_{2}(1)$ & $-0,00457$ & $-0,00455$ & $-0,00457$ & $-0,00457$ \\
$\overline{\mathrm{u}}_{3}(1 / 2)$ & 0,919 & 0,915 & 0,919 & 0,919 \\
$\bar{\sigma}_{11}(0)$ & $-0,725$ & $-0,734$ & $-0,726$ & $-0,726$ \\
$\bar{\sigma}_{11}(1 / 3)$ & $-0,106$ & $-0,094$ & $-0,105$ & $-0,106$ \\
$\bar{\sigma}_{11}(2 / 3)$ & 0,104 & 0,092 & 0,103 & 0,103 \\
$\bar{\sigma}_{11}(1)$ & 0,726 & 0,735 & 0,727 & 0,726 \\
$\bar{\sigma}_{22}(0)$ & $-0,0122$ & $-0,0123$ & $-0,0122$ & $-0,0122$ \\
$\bar{\sigma}_{22}(1 / 3)$ & $-0,0435$ & $-0,0435$ & $-0,0435$ & $-0,0435$ \\
$\bar{\sigma}_{22}(2 / 3)$ & 0,0418 & 0,0418 & 0,0418 & 0,0418 \\
$\bar{\sigma}_{22}(1)$ & 0,0145 & 0,0146 & 0,0146 & 0,0145 \\
$\bar{\sigma}_{23}(1 / 2)$ & 0,0152 & 0,0125 & 0,0162 & 0,0151 \\
$\bar{\sigma}_{13}(1 / 2)$ & 0,420 & 0,435 & 0,419 & 0,420 \\
$\bar{\sigma}_{12}(0)$ & 0,0123 & 0,0123 & 0,0123 & 0,0123 \\
$\bar{\sigma}_{12}(1 / 3)$ & 0,0033 & 0,0032 & 0,0033 & 0,0033 \\
$\bar{\sigma}_{12}(2 / 3)$ & $-0,0030$ & $-0,0029$ & $-0,0030$ & $-0,0030$ \\
$\bar{\sigma}_{12}(1)$ & $-0,0120$ & $-0,0120$ & $-0,0120$ & $-0,0120$ \\
\hline & & & &
\end{tabular}

that the trend is identical to that in the two-dimensional case: very fast convergence properties for CDLn models between $\mathrm{n}=1$ and 2, optimal subdivisions for accurate calculations along the thickness being reached as soon as $\mathrm{n}=3$, two subdivisions in each layer may suffice among points reported in Tables 3 and 4 .

As for Problem 1, Problem 2 shows the efficiency of the proposed "Constrained Discrete Layer (CDL)" model to accurately compute displacements and stresses for thick laminates, keeping at most 27 unknowns in Eq. (19) for the above (Problem 2) $3 \mathrm{D}$ problem with $\mathrm{n}=3$ discretizations in each layer. Note that CDL1 and CDL2 require, in Eq. (19), for the above 3D problem, $9(\mathrm{n}=1)$ and $18(\mathrm{n}=2)$ unknowns, respectively. Using classic discrete layer modelling (i.e., not satisfying Eqs. (14) and (15)) based on quadratic Lagrangian approximation throughout thickness of the laminate as in this paper, we need 21;39 or 57 unknowns, respectively for the above 3D problem, in adopting 1, 2 or 3 subdivisions per layer, as in Problem 2 for CDL modelling. The reader may refer to Reddy $[1,7]$ about classic layerwise modelling based on Lagrangian discretization along the thickness of laminates. 


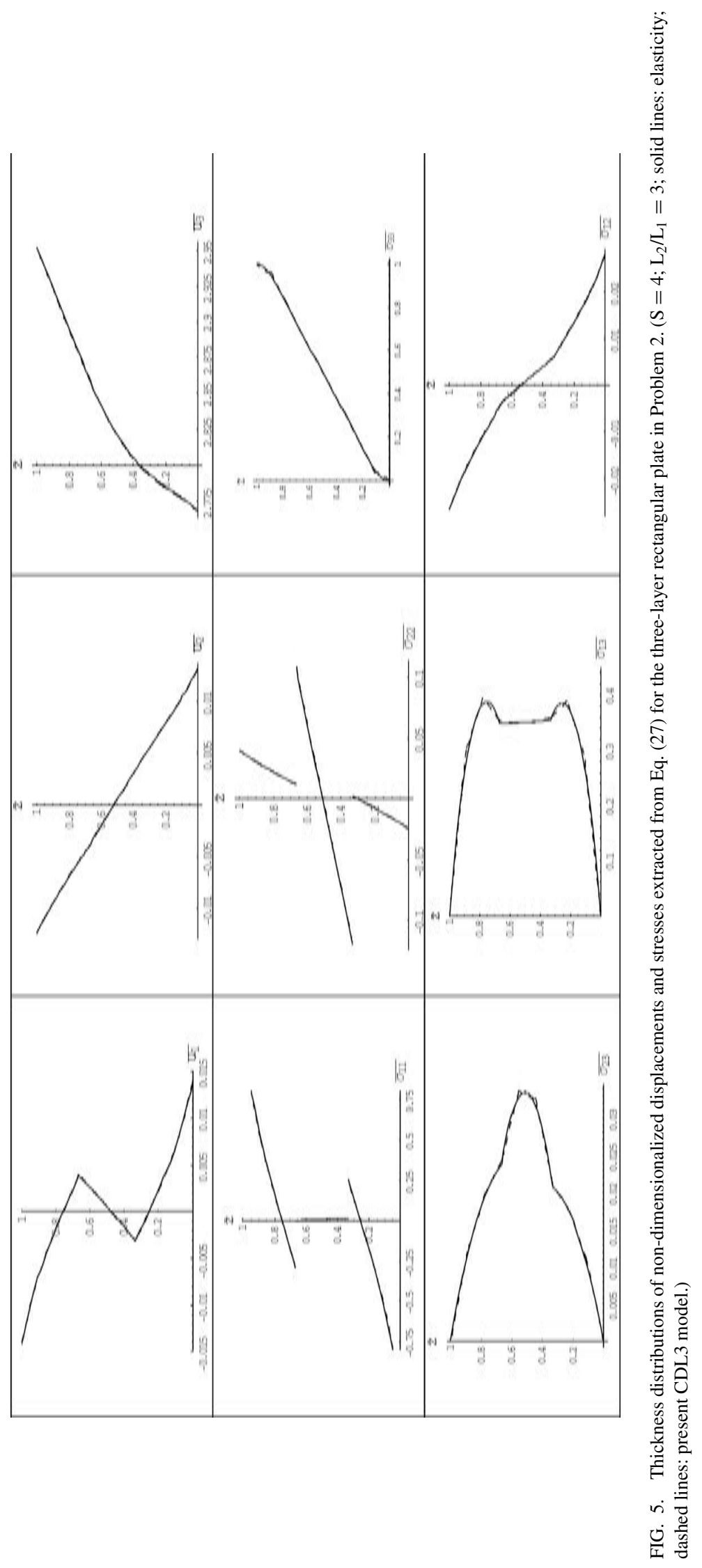




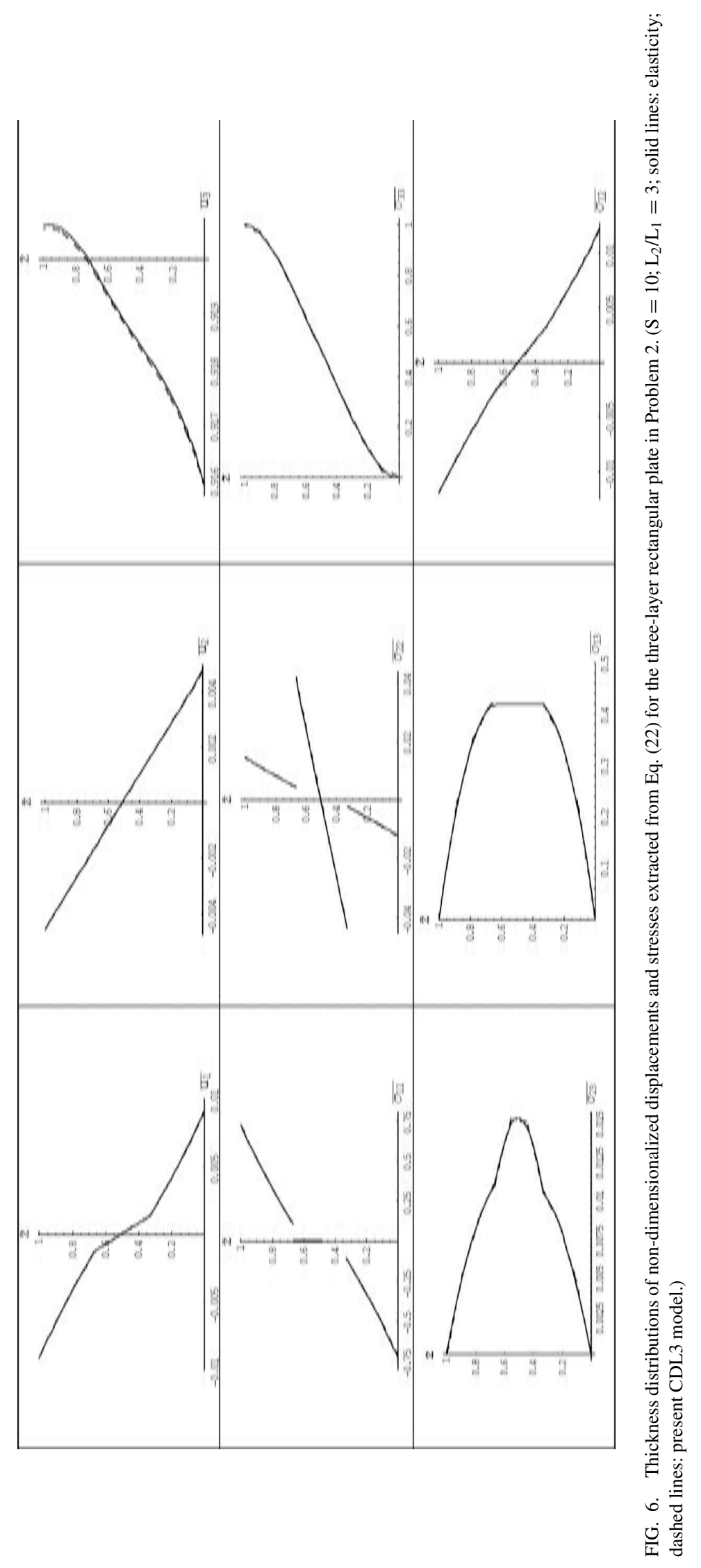




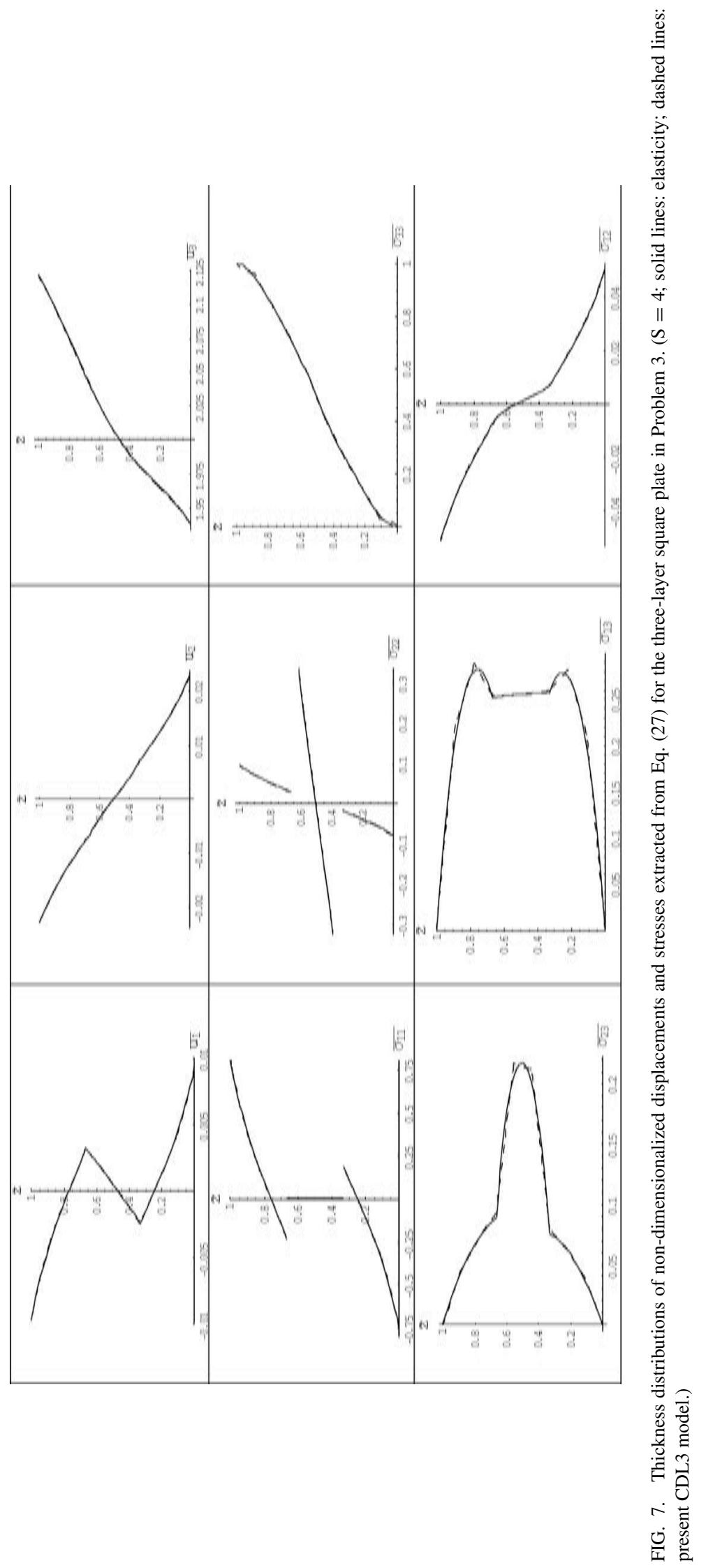




\subsection{Problem 3. Simply Supported Laminated $0^{\circ} / 90^{\circ} / 0^{\circ}$ Symmetric Square Plate under Sinusoidal Load}

Material data are same as those given for Problem 2 above [18], while geometric data are such that $\mathrm{L}_{2}=\mathrm{L}_{1}$. Two thickness ratios are again considered for thick laminates: 4 and 10. The layers have equal thickness, with fibers in the outer layers oriented in the $\mathrm{x}_{1}$-direction $\left(0^{\circ}\right)$ and those in the inner layer oriented in the $\mathrm{x}_{2}$-direction $\left(90^{\circ}\right)$. The plate is subjected to the doubly sinusoïdal distribution transverse loading expressed above. Tables 5 and 6 present non-dimensionalized displacements and stresses as in above Eq. (27).

Results are also presented in Figures 7 and 8 for two thickness ratios $(S=4$ and 10). These three-dimensional computations for square sandwich laminate show that the trend is identical to that in the two-dimensional case: very fast convergence properties for CDLn models between $\mathrm{n}=1$ and 2, optimal subdivisions for accurate calculations along the thickness being reached as soon as $\mathrm{n}=3$, two subdivisions in each layer may suffice at several points reported in Tables 5 and 6 .

As for above Problems 1 and 2, the efficiency of the proposed "Constrained Discrete Layer (CDL)" model is estab-

TABLE 5

Convergence of the CDLn model with respect to the number $\mathrm{n}=1,2,3$ of subdivisions in each layer. Calculations are extracted from Eq. (27). Problem 3: $S=4$; sandwich square plate

\begin{tabular}{lrrrr}
\hline & Elasticity & \multicolumn{1}{c}{ CDL1 } & \multicolumn{1}{c}{ CDL2 } & \multicolumn{1}{c}{ CDL3 } \\
\hline$\overline{\mathrm{u}}_{1}(0)$ & 0,00936 & 0,01028 & 0,00950 & 0,00941 \\
$\overline{\mathrm{u}}_{1}(1 / 3)$ & $-0,00242$ & $-0,00356$ & $-0,00245$ & $-0,00244$ \\
$\overline{\mathrm{u}}_{1}(2 / 3)$ & 0,00317 & 0,00438 & 0,00321 & 0,00319 \\
$\overline{\mathrm{u}}_{1}(1)$ & $-0,00969$ & $-0,01073$ & $-0,00985$ & $-0,00975$ \\
$\overline{\mathrm{u}}_{2}(0)$ & 0,0228 & 0,0210 & 0,0228 & 0,0228 \\
$\overline{\mathrm{u}}_{2}(1 / 3)$ & 0,0072 & 0,0077 & 0,0072 & 0,0072 \\
$\overline{\mathrm{u}}_{2}(2 / 3)$ & $-0,0066$ & $-0,0071$ & $-0,0067$ & $-0,0067$ \\
$\overline{\mathrm{u}}_{2}(1)$ & $-0,0228$ & $-0,0210$ & $-0,0228$ & $-0,0228$ \\
$\overline{\mathrm{u}}_{3}(1 / 2)$ & 2,006 & 1,900 & 2,003 & 2,005 \\
$\bar{\sigma}_{11}(0)$ & $-0,755$ & $-0,826$ & $-0,766$ & $-0,759$ \\
$\bar{\sigma}_{11}(1 / 3)$ & 0,190 & 0,279 & 0,193 & 0,192 \\
$\bar{\sigma}_{11}(2 / 3)$ & $-0,230$ & $-0,324$ & $-0,233$ & $-0,232$ \\
$\bar{\sigma}_{11}(1)$ & 0,801 & 0,881 & 0,813 & 0,805 \\
$\bar{\sigma}_{22}(0)$ & $-0,079$ & $-0,074$ & $-0,079$ & $-0,079$ \\
$\bar{\sigma}_{22}(1 / 3)$ & $-0,556$ & $-0,597$ & $-0,562$ & $-0,559$ \\
$\bar{\sigma}_{22}(2 / 3)$ & 0,534 & 0,574 & 0,540 & 0,537 \\
$\bar{\sigma}_{22}(1)$ & 0,095 & 0,091 & 0,095 & 0,095 \\
$\bar{\sigma}_{23}(1 / 2)$ & 0,217 & 0,122 & 0,249 & 0,215 \\
$\bar{\sigma}_{13}(1 / 2)$ & 0,256 & 0,267 & 0,254 & 0,255 \\
$\bar{\sigma}_{12}(0)$ & 0,051 & 0,049 & 0,051 & 0,051 \\
$\bar{\sigma}_{12}(1 / 3)$ & 0,0074 & 0,0064 & 0,0075 & 0,0075 \\
$\bar{\sigma}_{12}(2 / 3)$ & $-0,0055$ & $-0,0043$ & $-0,0055$ & $-0,0055$ \\
$\bar{\sigma}_{12}(1)$ & $-0,0511$ & $-0,0499$ & $-0,0513$ & $-0,0512$ \\
\hline
\end{tabular}

\section{TABLE 6}

Convergence of the CDLn model with respect to the number $\mathrm{n}=1,2,3$ of subdivisions in each layer. Calculations are extracted from Eq. (27). Problem 3: $\mathrm{S}=10$; sandwich square plate

\begin{tabular}{lrrrr}
\hline & Elasticity & \multicolumn{1}{c}{ CDL1 } & CDL2 & \multicolumn{1}{c}{ CDL3 } \\
\hline$\overline{\mathrm{u}}_{1}(0)$ & 0,00936 & 0,01028 & 0,00950 & 0,00941 \\
$\overline{\mathrm{u}}_{1}(1 / 3)$ & $-0,00242$ & $-0,00356$ & $-0,00245$ & $-0,00244$ \\
$\overline{\mathrm{u}}_{1}(2 / 3)$ & 0,00317 & 0,00438 & 0,00321 & 0,00319 \\
$\overline{\mathrm{u}}_{1}(1)$ & $-0,00969$ & $-0,01073$ & $-0,00985$ & $-0,00975$ \\
$\overline{\mathrm{u}}_{2}(0)$ & 0,0228 & 0,0210 & 0,0228 & 0,0228 \\
$\overline{\mathrm{u}}_{2}(1 / 3)$ & 0,0072 & 0,0077 & 0,0072 & 0,0072 \\
$\overline{\mathrm{u}}_{2}(2 / 3)$ & $-0,0066$ & $-0,0071$ & $-0,0067$ & $-0,0067$ \\
$\overline{\mathrm{u}}_{2}(1)$ & $-0,0228$ & $-0,0210$ & $-0,0228$ & $-0,0228$ \\
$\overline{\mathrm{u}}_{3}(1 / 2)$ & 2,006 & 1,900 & 2,003 & 2,005 \\
$\bar{\sigma}_{11}(0)$ & $-0,755$ & $-0,826$ & $-0,766$ & $-0,759$ \\
$\bar{\sigma}_{11}(1 / 3)$ & 0,190 & 0,279 & 0,193 & 0,192 \\
$\bar{\sigma}_{11}(2 / 3)$ & $-0,230$ & $-0,324$ & $-0,233$ & $-0,232$ \\
$\bar{\sigma}_{11}(1)$ & 0,801 & 0,881 & 0,813 & 0,805 \\
$\bar{\sigma}_{22}(0)$ & $-0,079$ & $-0,074$ & $-0,079$ & $-0,079$ \\
$\bar{\sigma}_{22}(1 / 3)$ & $-0,556$ & $-0,597$ & $-0,562$ & $-0,559$ \\
$\bar{\sigma}_{22}(2 / 3)$ & 0,534 & 0,574 & 0,540 & 0,537 \\
$\bar{\sigma}_{22}(1)$ & 0,095 & 0,091 & 0,095 & 0,095 \\
$\bar{\sigma}_{23}(1 / 2)$ & 0,217 & 0,122 & 0,249 & 0,215 \\
$\bar{\sigma}_{13}(1 / 2)$ & 0,256 & 0,267 & 0,254 & 0,255 \\
$\bar{\sigma}_{12}(0)$ & 0,051 & 0,049 & 0,051 & 0,051 \\
$\bar{\sigma}_{12}(1 / 3)$ & 0,0074 & 0,0064 & 0,0075 & 0,0075 \\
$\bar{\sigma}_{12}(2 / 3)$ & $-0,0055$ & $-0,0043$ & $-0,0055$ & $-0,0055$ \\
$\bar{\sigma}_{12}(1)$ & $-0,0511$ & $-0,0499$ & $-0,0513$ & $-0,0512$ \\
\hline & & & &
\end{tabular}

lished to accurately compute displacements and stresses for thick laminates.

\subsection{Problem 4. Cylindrical Bending of a Simply Supported Two-Layers $90^{\circ} / 0^{\circ}$ Laminate under a Sinusoidal Load}

In this problem (see [18]), a bi-directional two layer laminate is considered with the $\mathrm{T}=90^{\circ}$ and $\mathrm{L}=0^{\circ}$ directions aligned parallel to the $\mathrm{x}_{1}$-axis in the top and bottom layers, respectively, the layers being of equal thickness. Material properties and loading conditions are the same as those in Problem 1. Only the thickness ratio $L_{1} / h=4$ is tested in this Problem. Results are presented in Figure 9. Comparisons are shown between exact calculations and our CDL solution, by using either one, three, or four subdivisions in each layer. It is established for this difficult problem as well, that the proposed constrained discrete layer model converges towards the exact calculations, for thick laminates. But this problem as is known appears very difficult, because the convergence of stresses is slower than in the above problems. 


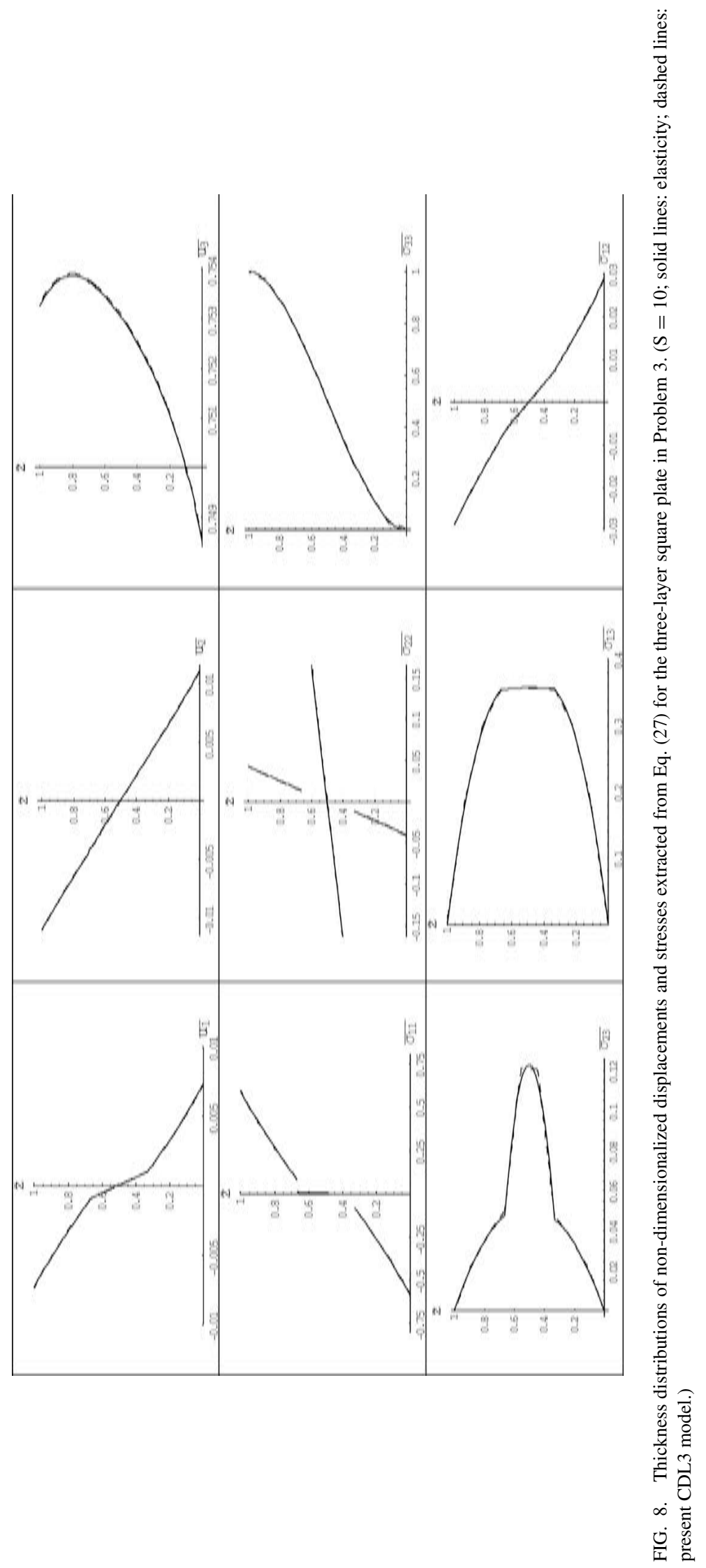




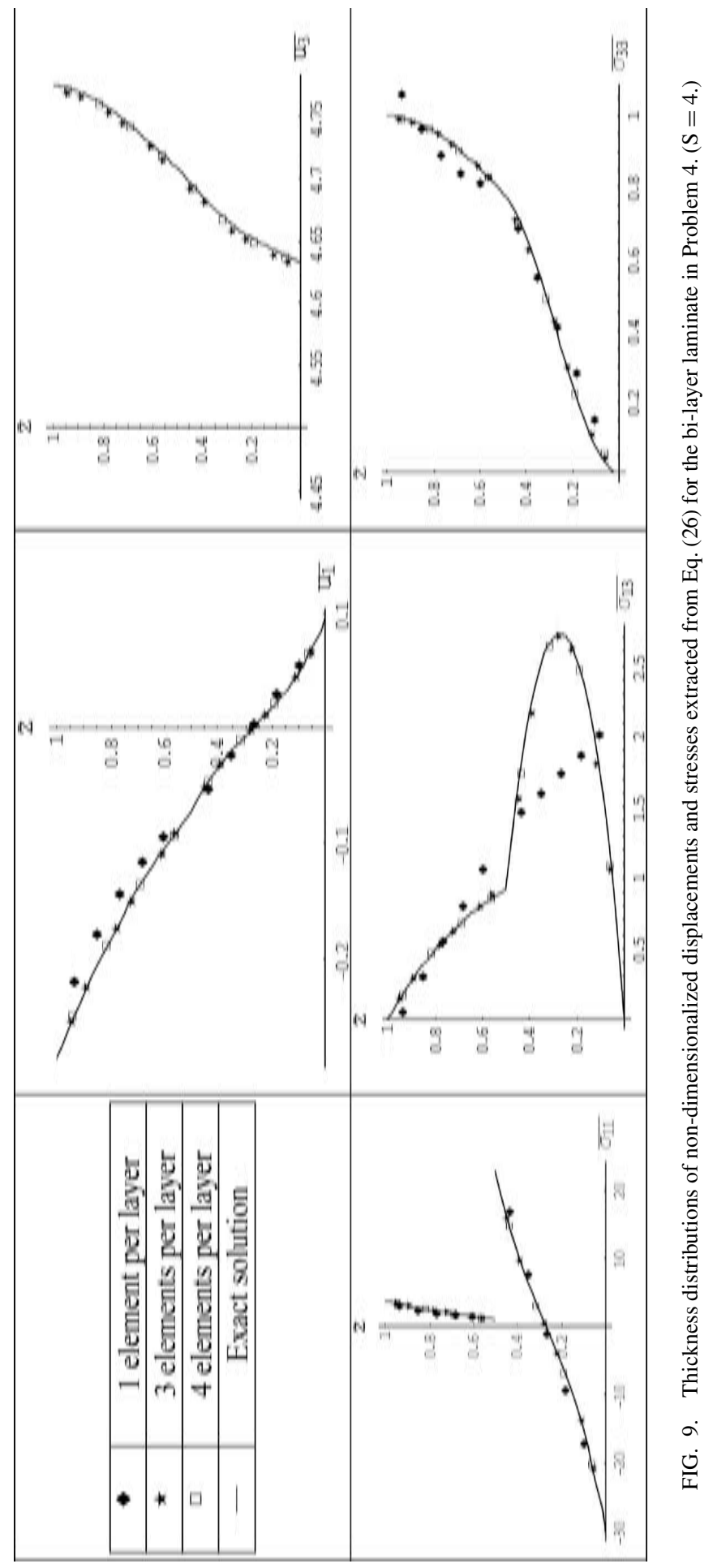




\subsection{Problem 5. Thermoelastic Response of a Bi-Directional Two-Layer $90^{\circ} / 0^{\circ}$ Laminate Subjected to Both Sinusoidal Thermal and Mechanical Loadings}

To evaluate our approach in thermoelasticity, we again consider the bi-layer analyzed in elasticity in the above Problem 4, but boundary conditions are now expressed as follows:

\section{- mechanical boundary conditions:}

$$
\begin{cases}\sigma_{13}\left(\mathrm{x}_{1}, 0\right)=0 & \mathrm{u}_{3}\left(\mathrm{x}_{1}, 0\right)=0 \\ \sigma_{13}\left(\mathrm{x}_{1}, \mathrm{~h}\right)=0 & \sigma_{33}\left(\mathrm{x}_{1}, \mathrm{~h}\right)=\mathrm{p} \operatorname{Sin}\left(\frac{\pi x_{1}}{L_{1}}\right)\end{cases}
$$

- thermal boundary conditions :

$$
\left\{\begin{array}{l}
\mathrm{T}\left(\mathrm{x}_{1}, 0\right)=-\mathrm{T}_{0} \operatorname{Sin}\left(\frac{\pi \mathrm{x}_{1}}{\mathrm{~L}_{1}}\right) \\
\mathrm{T}\left(\mathrm{x}_{1}, h\right)=\mathrm{T}_{0} \operatorname{Sin}\left(\frac{\pi \mathrm{x}_{1}}{\mathrm{~L}_{1}}\right)
\end{array}\right.
$$

where $\mathrm{T}\left(\mathrm{L}_{1} / 2, \mathrm{~h}\right) / \mathrm{T}_{0}=1$.

Mechanical properties have been given at the top of Section 4. From [13], thermal properties are: $\mathrm{k}_{\mathrm{L}}=36.42 \mathrm{Wm}^{-1}{ }^{\circ} \mathrm{C}^{-1}$; $\mathrm{k}_{\mathrm{T}}=0.96 \mathrm{Wm}^{-1}{ }^{\circ} \mathrm{C}^{-1} ; \alpha_{\mathrm{L}}=0.5710^{-6 \circ} \mathrm{C}^{-1} ; \alpha_{\mathrm{T}}=35.6$ $10^{-6 \circ} \mathrm{C}^{-1}$. For this kind of supported antisymmetric bi-layer $\left(90^{\circ} / 0^{\circ}\right)$ laminated composite subjected to the above thermal and mechanical loadings, we determine an exact thermoelastic solution from [13] by using the Mathematica package, and a constrained discrete layer solution from the calculations summarized above in Eqs. (20) and (21) (also see [11]). Corresponding temperature distributions computed from Eqs. (20) and (21), are then shown in Figure 10. Results from the present constrained discrete layer modelling for linearly thermoelastic analysis are now compared with exact calculations for displacement and thermal stress distributions through the thickness of the bi-layer laminate as depicted in Figure 11. It is concluded again on good convergence properties for the constrained discrete layer approach, as soon as the number of subdivisions in each layer increases up to 6, having only one independent generalized temperature per subdivision, and two independent generalized displacements per subdivision.

\subsection{Problem 6. Thermoelastic Response of a Three-dimensional Two-Layer $90^{\circ} / 0^{\circ}$ Laminate Subjected to Both Doubly Sinusoïdal Thermal and Mechanical Loads}

In this section, we consider the above laminate as a threedimensional medium. Boundary conditions are as follows.

- mechanical boundary conditions:

$\left\{\begin{array}{l}\sigma_{13}\left(\mathrm{x}_{1}, \mathrm{x}_{2}, 0\right)=\sigma_{13}\left(\mathrm{x}_{1}, \mathrm{x}_{2}, \mathrm{~h}\right)=\sigma_{23}\left(\mathrm{x}_{1}, \mathrm{x}_{2}, 0\right)=\sigma_{23}\left(\mathrm{x}_{1}, \mathrm{x}_{2}, \mathrm{~h}\right)=0 \\ \mathrm{u}_{1}\left(\mathrm{x}_{1}, 0,0\right)=\mathrm{u}_{1}\left(\mathrm{x}_{1}, \mathrm{~L}_{2}, 0\right)=\mathrm{u}_{2}\left(0, \mathrm{x}_{2}, 0\right)=\mathrm{u}_{2}\left(\mathrm{~L}_{1}, \mathrm{x}_{2}, 0\right)=0 \\ \mathrm{u}_{3}\left(\mathrm{x}_{1}, \mathrm{x}_{2}, 0\right)=0 \text { and } \sigma_{33}\left(\mathrm{x}_{1}, \mathrm{x}_{2}, \mathrm{~h}\right)=\mathrm{pSin}\left(\frac{\pi \mathrm{x}_{1}}{\mathrm{~L}_{1}}\right) \operatorname{Sin}\left(\frac{\pi \mathrm{x}_{2}}{\mathrm{~L}_{2}}\right)\end{array}\right.$

- thermal boundary conditions:

$\left\{\begin{array}{l}\mathrm{T}\left(0, \mathrm{x}_{2}, \mathrm{x}_{3}\right)=\mathrm{T}\left(\mathrm{L}_{1}, \mathrm{x}_{2}, \mathrm{x}_{3}\right)=\mathrm{T}\left(\mathrm{x}_{1}, 0, \mathrm{x}_{3}\right)=\mathrm{T}\left(\mathrm{x}_{1}, \mathrm{~L}_{2}, \mathrm{x}_{3}\right)=0 \\ \mathrm{~T}\left(\mathrm{x}_{1}, \mathrm{x}_{2}, 0\right)=-\mathrm{T}_{0} \operatorname{Sin}\left(\frac{\pi \mathrm{x}_{1}}{\mathrm{~L}_{1}}\right) \operatorname{Sin}\left(\frac{\pi \mathrm{x}_{2}}{\mathrm{~L}_{2}}\right) \\ \mathrm{T}\left(\mathrm{x}_{1}, \mathrm{x}_{2}, \mathrm{~h}\right)=\mathrm{T}_{0} \operatorname{Sin}\left(\frac{\pi \mathrm{x}_{1}}{\mathrm{~L}_{1}}\right) \operatorname{Sin}\left(\frac{\pi \mathrm{x}_{2}}{\mathrm{~L}_{2}}\right)\end{array}\right.$

The temperature distribution for this problem has been obtained from Eqs. (20) and (21), and is shown in Figure 12. The thermoelastic analysis corresponding to this present problem is shown in Figure 13. Results from our CDL modelling are compared both with exact calculations and the standard layerwise model, called here the DL model (see [1, 6]). It is concluded that the CDL model is better than the DL on stress distributions, for a reduced computational model size. Finally, the proposed constrained discrete layer modelling allows reducing the size problem for laminates without any loss of accuracy, and gives very good thickness distributions for both displacements, stresses, temperatures, as both interface and top and bottom boundary conditions are exactly satisfied. The capability of this modelling in capturing particular transverse shear stress distributions for

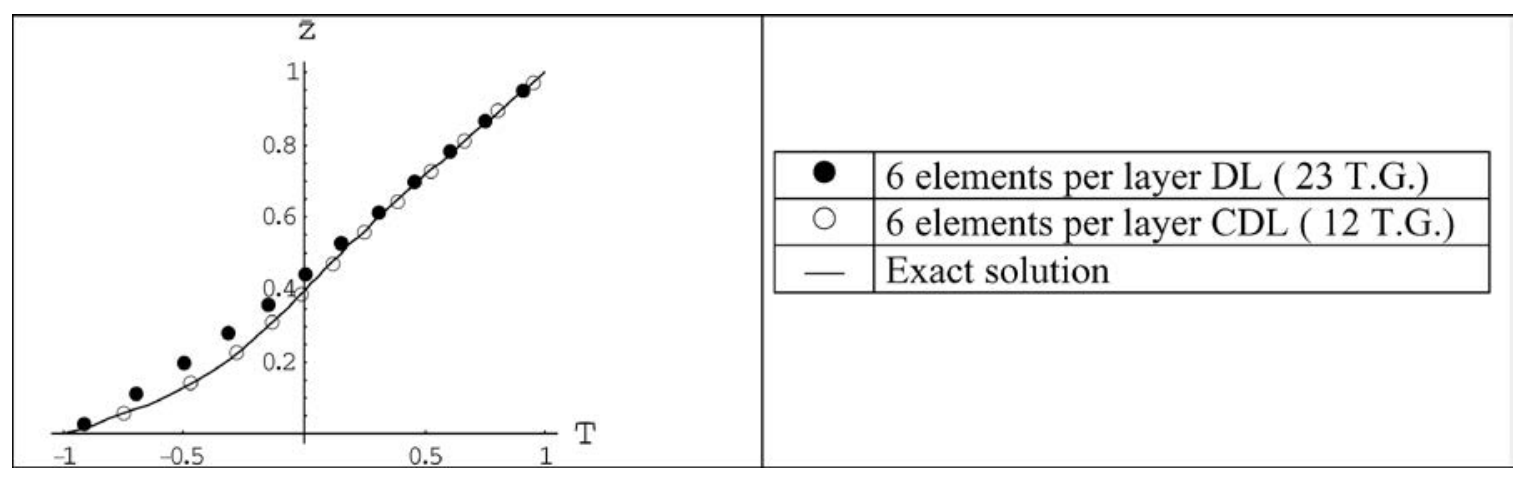

FIG. 10. Temperature distribution along the thickness of the bi-directional bi-layer laminate in Problem 5, at its mid-length. 


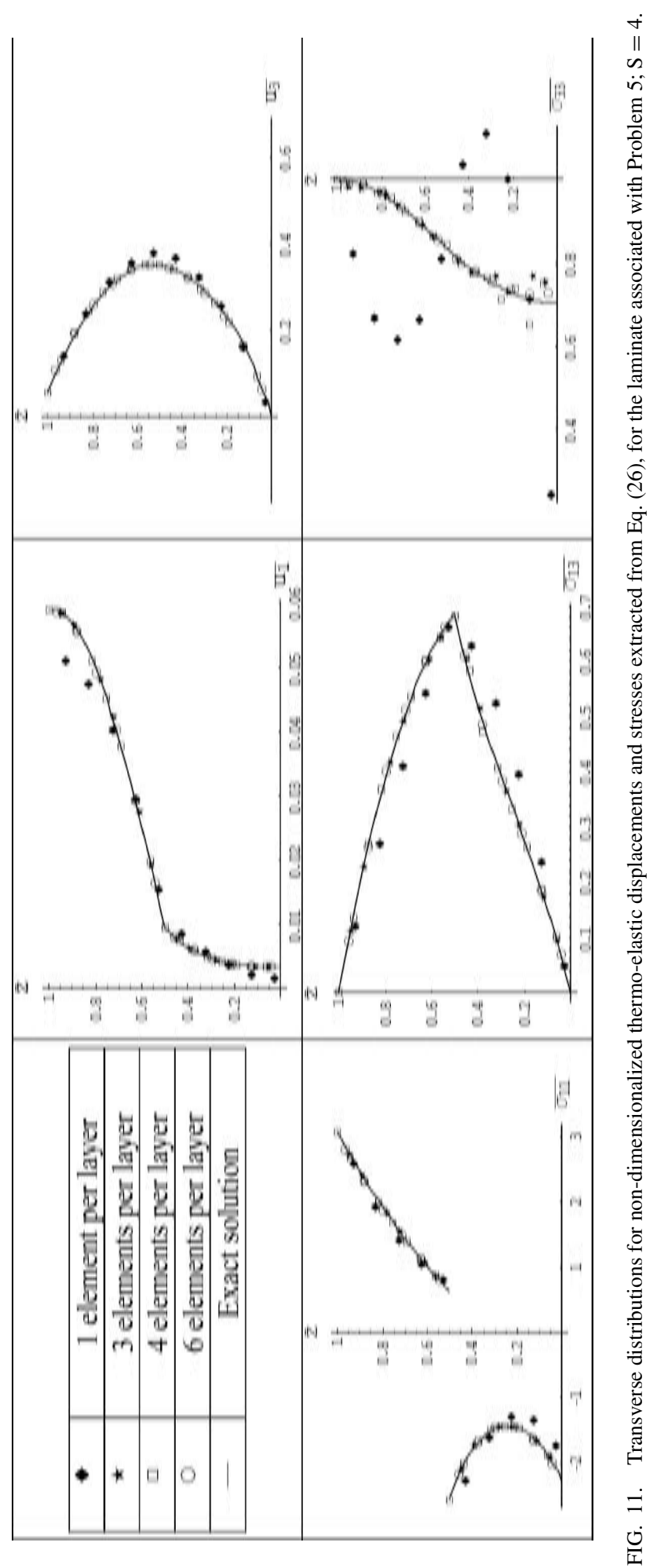




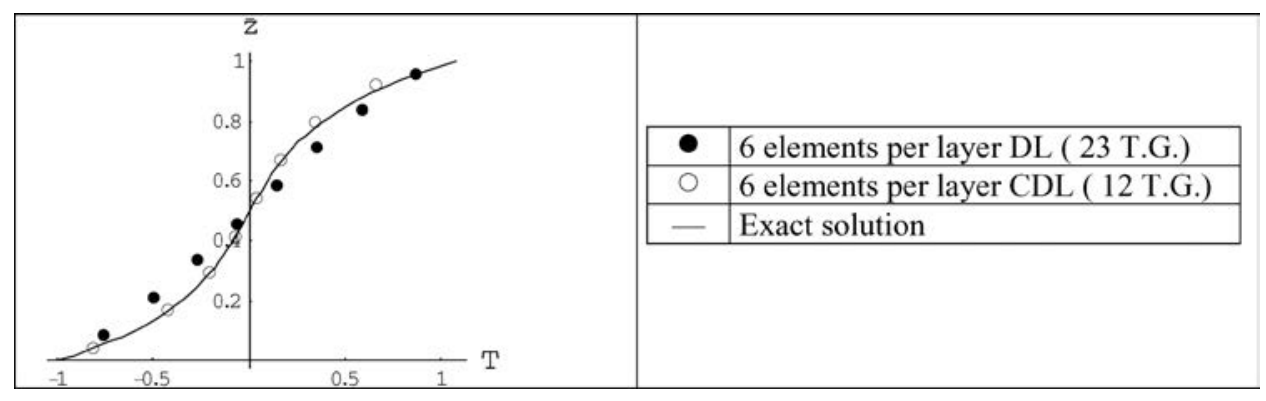

FIG. 12. Temperature distribution along the thickness of the three-dimensional bi-layer laminate in Problem 6, at its center.

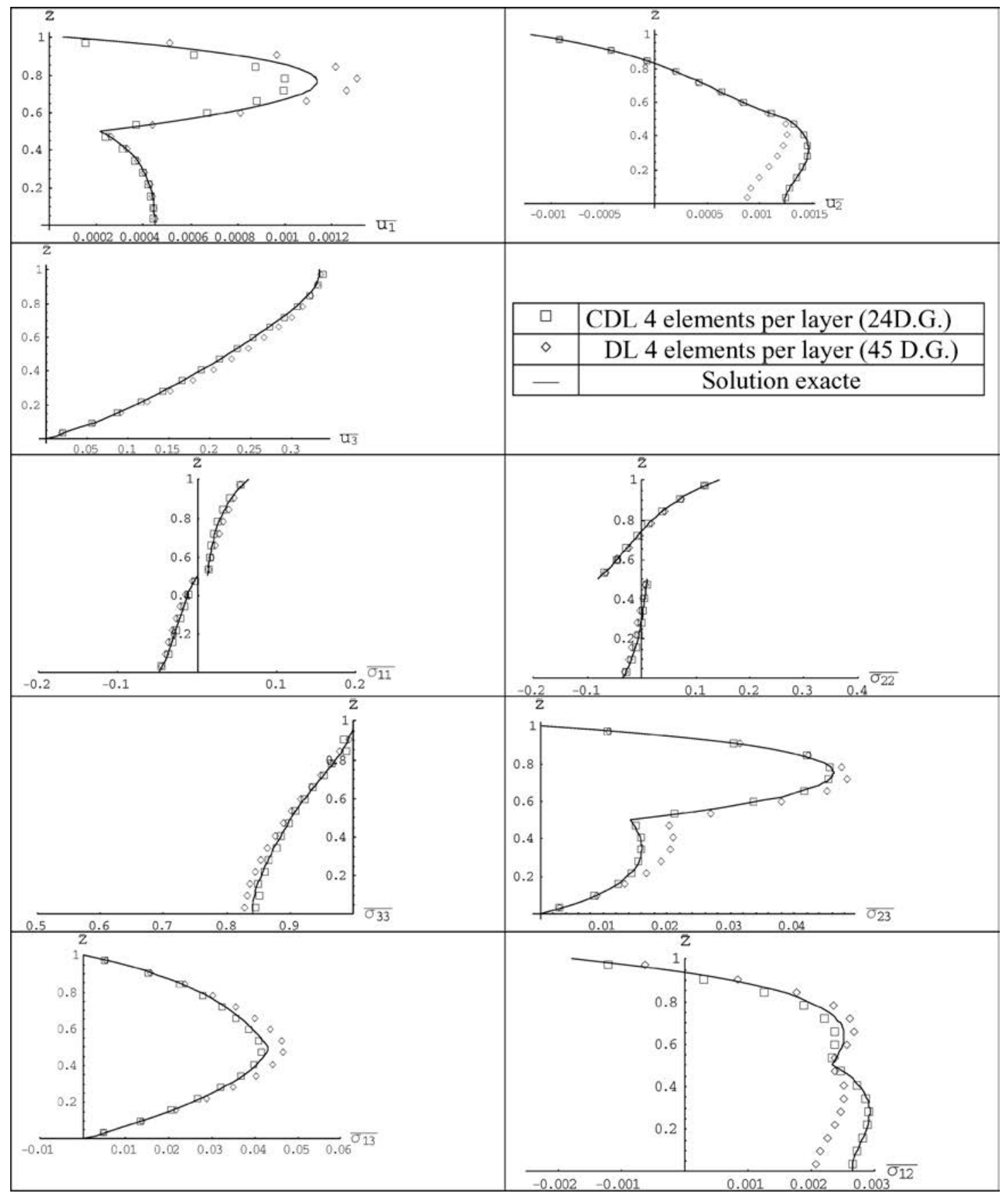

FIG. 13. Transverse distributions for non-dimensionalized thermo-elastic displacements and stresses extracted from Eq. (27), for the laminate associated with Problem 6; $\mathrm{S}=4$. 
very thick laminates must be remarked (here, thickness ratio 4), see Figures 3 to 13.

\section{CONCLUSIONS}

Discrete layer solutions are presented for static responses of linearly elastic and thermoelastic multilayered composite plates, and have been found in good agreement with exact threedimensional solutions.

The proposed constrained discrete layer modelling is new, and allows satisfying exactly all the interface and boundary conditions for temperature, heat flux, displacements and stresses. Using thickness subdivisions along the thickness of the laminate from quadratic Lagrangian interpolations in the manner of quadratic one-dimensional finite elements through the thickness, interface and boundary conditions are exploited to reduce the number of independent generalized temperatures and independent generalized displacements. The result is that independent generalized temperatures and displacements are only those at the medium node of the subdivision. The boundary value problem is then solved from standard variational theorems (for thermal and mechanical analyses), assuming double Fourier series expansions for both temperature, displacement and loads, in respect to the surface coordinates. Adopting for example one subdivision per layer in a laminate having $\mathrm{N}$ layers, and quadratic Lagrangian interpolation along the thickness of this laminate, the constrained discrete layer modelling leads to $\mathrm{N}$ independent generalized temperatures, $3 \mathrm{~N}$ independent generalized displacements, while the standard discrete-layer modelling requires $2 \mathrm{~N}-1$ independent generalized temperatures and $3(2 \mathrm{~N}+1)$ independent generalized displacements. This is the main advantage of the constrained discrete layer approach, in addition to the exact satisfaction of interface and boundary conditions. Finally, the constrained discrete layer modelling has been successfully extended to thermoelastic analysis of laminates, by computing temperature distributions followed by a thermomechanical response, using the same method of discretisation, and comparing it with exact thermoelastic calculations.

\section{REFERENCES}

1. Reddy, J. N., Mechanics of Laminated Composite Plates and Shells: Theory and Analysis. (Second edtion) CRC Press, Boca Raton, FL (2004).

2. Reddy, J. N., and Arciniega R. A., "Shear deformation plate and shell theories: Stavsky to present," Mechanics of Advanced Materials and Structures 11(6), 535-516 (2004).

3. Carrera, E., "Theories and finite elements for multilayered, anisotropic, composite plates and shells," Arch. Comput. Meth. Engng 9(2), 87-140 (2002).

4. Carrera, E., "Temperature profile influence on layered plates response considering classical and advanced theories," AIAA Journal 40(9), 1885-1896 (2002) .

5. Carrera, E., "Closed-form solutions to assess multilayered-plate theories for various thermal stress problems," Journal of Thermal Stresses 27, 10011031 (2004).
6. Robbins, D. H., and Reddy, J. N., "Modelling of thick composites using a layerwise laminate theory," Int. J. Numer. Methods. Engng. 36, 655-677 (1993).

7. Reddy, J. N., "A generalization of two-dimensional theories of laminated composite plates," Commun. Appl. Numer. Methods 3, 173-180 (1987).

8. Saravanos, D. A., Heyliger, P. R., and Hopkins, D. A., "Layerwise mechanics and finite element for dynamic analysis of piezoelectric composite plates," Int. J. Solids and Structures 34(3), 359-378 (1997).

9. Garcia Lage, R., Mota Soares, C. M., Mota Soares, C. A., and Reddy, J. N., "Layerwise partial mixed finite element analysis of magneto-electro-elastic plates," Computers \& Structures 82, 1293-1301 (2004).

10. Semedo Garção, J. E., Mota Soares, C. M., Mota Soares, C. A., and Reddy, J. N., "Analysis of laminated adaptive plate structures using layerwise finite element models," Computers and Structures 82(23-26), 1939-1959 (2004).

11. Blanc, M., and Touratier, M., "A constrained discrete layer model for heat conduction in laminated composites," Computers \& Structures 83, 17051718 (2005).

12. Xu, K., Noor, A. K., and Tang, Y. Y., "Three-dimensional solutions for coupled thermoelectroelastic response of multilayered plates," Computer Methods in Applied Mechanics and Engineering 126, 355-371 (1995).

13. Tungikar, V. B., Rao, K. M., "Three-dimensional exact solution of thermal stresses in rectangular composite laminate," Composite Structures 27, 419430 (1994)

14. Savoia, M., and Reddy, J. N., "Three-dimensional thermal analysis of laminated composite plates," Int. J. Solids Structures, 32(5), 593-608 (1995).

15. Matsunaga, H., "A comparison between 2-D single-layer and 3-D layerwise theories for computing interlaminar stresses of laminated composite and sandwich plates subjected to thermal loadings," Composite Structures 64, 161-177 (2004).

16. Touratier, M., "A refined theory for thick composite plates," Mechanics Research Communications 15, 229-236 (1988).

17. Pagano, N. J., "Exact solutions for composite laminates in cylindrical bending," J. Composite Materials 3, 398-411 (1969).

18. Pagano, N. J., "Exact solutions for rectangular bidirectional composites and sandwich plates," J. Composite Materials 4, 20-34 (1970).

19. Carrera, E., "Single-layer vs multi-layers plate modelings on the basis of Reissner's mixed theorem," American Institute of Aeronautics and Astronautics Journal 38, 342-352 (2000).

20. Wolfram, S., Mathematica a System for Doing Mathematics by Computer, Addison-Wesley, Redwood City, California (1991).

21. Ray, M. C., and Reddy, J. N., "Optimal control of thin circular cylindrical laminated composite shells using active constrained layer damping treatment," Smart Materials and Structures 13, 64-72 (2004).

22. Ray, M. C., and Reddy, J. N., "Effect of delamination on the active constrained layer damping of laminated composite beams," AIAA Journal 42(6), 1219-1226 (2004).

\section{APPENDIX}

$$
\begin{aligned}
& \underline{\mathrm{T}}_{(\mathrm{rs}) \mathrm{i}}^{\mathrm{T}} \text { is the line } \mathrm{i}(\mathrm{i}=1,2,3) \underline{\underline{\mathrm{T}}}_{(\mathrm{rs})} \\
\underline{\hat{\mathrm{C}}}_{(\mathrm{rs}) \mathrm{i} 3}^{(\mathrm{j})}= & \left(\sum_{\alpha=1,2} \mathrm{C}_{\alpha \alpha 33}^{(\mathrm{j})} \underline{\mathrm{T}}_{(\mathrm{rs}) \alpha, \alpha}^{\mathrm{T}} \mathrm{l}_{\mathrm{b}}^{\mathrm{j}}+\mathrm{C}_{3333}^{(\mathrm{j})} \underline{\mathrm{T}}_{(\mathrm{rs}) 3}^{\mathrm{T}} 3_{\mathrm{b}}^{\mathrm{j}^{\prime}}\right)_{\mathrm{z}=\mathrm{z}_{\mathrm{j}}} \\
\underline{\hat{\mathrm{C}}}_{(\mathrm{rs}) \mathrm{i} 3}^{(\mathrm{j}+1) \mathrm{T}}= & \left(\sum_{\alpha=1,2} \mathrm{C}_{\alpha \alpha 33}^{(\mathrm{j})} \underline{\mathrm{T}}_{(\mathrm{rs}) \alpha, \alpha}^{\mathrm{T}} \mathrm{l}_{\mathrm{t}}^{\mathrm{j}}+\mathrm{C}_{3333}^{(\mathrm{j})} \underline{\mathrm{T}}_{(\mathrm{rs}) 3}^{\mathrm{T}} \mathrm{l}_{\mathrm{t}}^{\mathrm{j}^{\prime}}\right. \\
& \left.-\sum_{\alpha=1,2} \mathrm{C}_{\alpha \alpha 33}^{(\mathrm{j}+1)} \underline{\mathrm{T}}_{(\mathrm{rs}) \alpha, \alpha}^{\mathrm{T}} \mathrm{l}_{\mathrm{b}}^{\mathrm{j}+1}-\mathrm{C}_{3333}^{(\mathrm{j}+1)} \underline{\mathrm{T}}_{(\mathrm{rs}) 3}^{\mathrm{T}} \mathrm{l}_{\mathrm{t}}^{\mathrm{j}+\mathrm{l}^{\prime}}\right)_{\mathrm{z}=\mathrm{z}_{\mathrm{j}}}
\end{aligned}
$$




$$
\begin{aligned}
& \underline{\hat{\mathrm{C}}}_{(\mathrm{rs}) \mathrm{i} 3}^{(\mathrm{j}+2) \mathrm{T}}=\left(\sum_{\alpha=1,2} \mathrm{C}_{\alpha \alpha 33}^{(\mathrm{j}+1)} \underline{\mathrm{T}}_{(\mathrm{rs}) \alpha, \alpha}^{\mathrm{T}} \mathrm{l}_{\mathrm{t}}^{\mathrm{j}+1}+\mathrm{C}_{3333}^{(\mathrm{j}+1)} \underline{\mathrm{T}}_{(\mathrm{rs}) 3}^{\mathrm{T}} \mathrm{l}_{\mathrm{t}}^{\mathrm{j}+1^{\prime}}\right)_{\mathrm{z}=\mathrm{z}_{\mathrm{j}}} \\
& \underline{\hat{\mathrm{B}}}_{(\mathrm{rs}) 33}^{(\mathrm{j}) \mathrm{T}}=\left(\sum_{\alpha=1,2} \mathrm{C}_{\alpha \alpha 33}^{(\mathrm{j})} \underline{\mathrm{T}}_{(\mathrm{rs}) \alpha, \alpha}^{\mathrm{T}} 1_{\mathrm{m}}^{\mathrm{j}}+\mathrm{C}_{3333}^{(\mathrm{j})} \underline{\mathrm{T}}_{(\mathrm{rs}) 3}^{\mathrm{T}} 3_{\mathrm{m}}^{\mathrm{j}^{\prime}}\right)_{\mathrm{z}=\mathrm{z}_{\mathrm{j}}} \\
& \underline{\hat{B}}_{(\mathrm{rs}) 33}^{(\mathrm{j}+1) \mathrm{T}}=\left(\sum_{\alpha=1,2} \mathrm{C}_{\alpha \alpha 33}^{(\mathrm{j})} \underline{\mathrm{T}}_{(\mathrm{rs}) \alpha, \alpha}^{\mathrm{T}} \mathrm{1}_{\mathrm{m}}^{\mathrm{j}+1}+\mathrm{C}_{3333}^{(\mathrm{j})} \underline{\mathrm{T}}_{(\mathrm{rs}) 3}^{\mathrm{T}} \mathrm{1}_{\mathrm{m}}^{\mathrm{j}+1^{\prime}}\right)_{\mathrm{z}=\mathrm{z}_{\mathrm{j}}} \\
& \underline{\hat{\mathrm{C}}}_{(\mathrm{rs}) \alpha 3}^{(\mathrm{j}) \mathrm{T}}=\mathrm{C}_{\alpha 3 \alpha 3}^{(\mathrm{j})}\left(\underline{\mathrm{T}}_{(\mathrm{rs}) \alpha}^{\mathrm{T}} \mathrm{l}_{\mathrm{b}}^{\mathrm{j}^{\prime}}+\underline{\mathrm{T}}_{(\mathrm{rs}) 3, \alpha}^{\mathrm{T}} \mathrm{l}_{\mathrm{b}}^{\mathrm{j}}\right)_{\mathrm{z}=\mathrm{z}_{\mathrm{j}}}
\end{aligned}
$$

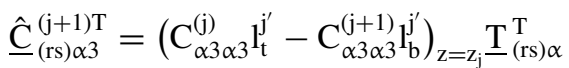

$$
\begin{aligned}
& +\left(\mathrm{C}_{\alpha 3 \alpha 3}^{(\mathrm{j})} \mathrm{l}_{\mathrm{t}}^{\mathrm{j}}-\mathrm{C}_{\alpha 3 \alpha 3}^{(\mathrm{j}+1)} \mathrm{l}_{\mathrm{b}}^{\mathrm{j}+1}\right)_{\mathrm{z}=\mathrm{z}_{\mathrm{j}}} \mathrm{T}_{(\mathrm{rs}) 3, \alpha}^{\mathrm{T}} \\
& \underline{\hat{\mathrm{C}}}_{(\mathrm{rs}) \alpha 3}^{(\mathrm{j}+2) \mathrm{T}}=\mathrm{C}_{\alpha 3 \alpha 3}^{(\mathrm{j}+1)}\left(\underline{\mathrm{T}}_{(\mathrm{rs}) \alpha}^{\mathrm{T}} \mathrm{l}_{\mathrm{t}}^{\mathrm{j}+1^{\prime}}+\underline{\mathrm{T}}_{(\mathrm{rs}) 3, \alpha}^{\mathrm{T}} \mathrm{l}_{\mathrm{t}}^{\mathrm{j}+1}\right)_{\mathrm{z}=\mathrm{z}_{\mathrm{j}}} \\
& \underline{\hat{\mathrm{B}}}_{(\mathrm{rs}) \alpha 3}^{(\mathrm{j}) \mathrm{T}}=\mathrm{C}_{\alpha 3 \alpha 3}^{\mathrm{j})}\left(\underline{\mathrm{T}}_{(\mathrm{rs}) \alpha}^{\mathrm{T}} \mathrm{1}_{\mathrm{m}}^{\mathrm{j}^{\prime}}+\underline{\mathrm{T}}_{(\mathrm{rs}) 3, \alpha}^{\mathrm{T}} \mathrm{1}_{\mathrm{m}}^{\mathrm{j}}\right)_{\mathrm{z}=\mathrm{z}_{\mathrm{j}}} \\
& \underline{\hat{\mathrm{B}}}_{(\mathrm{rs}) \alpha 3}^{(\mathrm{j}+1) \mathrm{T}}=\mathrm{C}_{\alpha 3 \alpha 3}^{(\mathrm{j}+1)}\left(\underline{\mathrm{T}}_{(\mathrm{rs}) \alpha}^{\mathrm{T}} \mathrm{1}_{\mathrm{m}}^{\mathrm{j}+\mathrm{1}^{\prime}}+\underline{\mathrm{T}}_{(\mathrm{rs}) 3, \alpha}^{\mathrm{T}} \mathrm{1}_{\mathrm{m}}^{\mathrm{j}+1}\right)_{\mathrm{z}=\mathrm{z}_{\mathrm{j}}} \\
& \alpha=1,2 ; \quad \underline{\mathrm{T}}_{(\mathrm{rs}) 3, \alpha}^{\mathrm{T}}=\frac{\partial \underline{\mathrm{T}}_{(\mathrm{rs}) 3}^{\mathrm{T}}}{\partial \mathrm{x}_{\alpha}}, \quad \mathrm{l}_{\mathrm{k}}^{\mathrm{j}^{\prime}}=\frac{\mathrm{dl}_{\mathrm{k}}^{\mathrm{j}}}{\mathrm{dz}}
\end{aligned}
$$

$$
\begin{aligned}
& \underline{\hat{\mathrm{C}}}_{(\mathrm{rs}) 33}^{\left(\mathrm{b}_{1} \text { or } \mathrm{N}_{\mathrm{N}}\right)}=\left(\sum_{\alpha=1,2} \mathrm{C}_{\alpha \alpha 33}^{(1 \text { or } \mathrm{N})} \underline{\mathrm{T}}_{(\mathrm{rs}) \alpha, \alpha}^{\mathrm{T}} \mathrm{l}_{\mathrm{b}}^{1 \text { or N }}\right.
\end{aligned}
$$

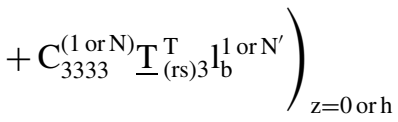

$$
\begin{aligned}
& \underline{\hat{\mathrm{C}}}_{(\mathrm{rs}) 33}^{\left(\mathrm{b}_{2} \text { or } \mathrm{t}_{\mathrm{N}+1}\right)}=\left(\sum_{\alpha=1,2} \mathrm{C}_{\alpha \alpha 33}^{(1 \text { or } \mathrm{N})} \underline{\mathrm{T}}_{(\mathrm{rs}) \alpha, \alpha}^{\mathrm{T}} \mathrm{l}_{\mathrm{t}}^{1 \text { or N }}\right.
\end{aligned}
$$

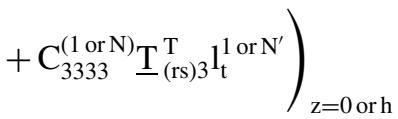

$$
\begin{aligned}
& \underline{\hat{B}}_{(\mathrm{rs}) 33}^{\left(\mathrm{b}_{\mathrm{t}} \text { or } \mathrm{t}_{\mathrm{N}}\right)}=\left(\sum_{\alpha=1,2} \mathrm{C}_{\alpha \alpha 33}^{(1 \text { or } \mathrm{N})} \underline{\mathrm{T}}_{(\mathrm{rs}) \alpha, \alpha}^{\mathrm{T}} 1_{\mathrm{m}}^{1 \text { or N }}\right. \\
& \left.+\mathrm{C}_{3333}^{(1 \text { or N })} \underline{\mathrm{T}}_{(\mathrm{rs}) 3}^{\mathrm{T}} 1_{\mathrm{m}}^{1 \text { or } \mathrm{N}^{\prime}}\right)_{\mathrm{z}=0 \text { or h }} \\
& \underline{\mathrm{C}}_{(\mathrm{rs}) \alpha 3}^{\left(\mathrm{b}_{1} \text { or }_{\mathrm{N}}\right)}=\mathrm{C}_{\alpha 3 \alpha 3}^{(1 \text { or } \mathrm{N})}\left(\underline{\mathrm{T}}_{(\mathrm{rs}) \alpha}^{\mathrm{T}} \mathrm{l}_{\mathrm{b}}^{1 \text { or } \mathrm{N}^{\prime}}+\underline{\mathrm{T}}_{(\mathrm{rs}) 3, \alpha}^{\mathrm{T}} \mathrm{l}_{\mathrm{b}}^{1 \text { or N }}\right)_{\mathrm{z}=0 \text { or h }} \\
& \underline{\mathrm{C}}_{(\mathrm{rs}) \alpha 3}^{\left(\mathrm{b}_{2} \text { or t }_{\mathrm{N}+1}\right)}=\mathrm{C}_{\alpha 3 \alpha 3}^{(1 \mathrm{or} \mathrm{N})}\left(\underline{\mathrm{T}}_{(\mathrm{rs}) \alpha}^{\mathrm{T}} 1_{\mathrm{t}}^{1 \text { or } \mathrm{N}^{\prime}}+\underline{\mathrm{T}}_{(\mathrm{rs}) 3, \alpha}^{\mathrm{T}} \mathrm{l}_{\mathrm{t}}^{1 \text { or N}}\right)_{\mathrm{z}=0 \text { or h }} \\
& \underline{\hat{\mathrm{B}}}_{(\mathrm{rs}) \alpha 3}^{\left(\mathrm{b}_{1} \text { or } \mathrm{N}_{\mathrm{N}}\right)}=\mathrm{C}_{\alpha 3 \alpha 3}^{(1 \text { or } \mathrm{N})}\left(\underline{\mathrm{T}}_{(\mathrm{rs}) 3, \alpha}^{\mathrm{T}} \mathrm{l}_{\mathrm{m}}^{1 \text { or N }}+\underline{\mathrm{T}}_{(\mathrm{rs}) \alpha}^{\mathrm{T}} 1_{\mathrm{m}}^{1 \text { or } \mathrm{N}^{\prime}}\right)_{\mathrm{z}=0 \text { or h }}
\end{aligned}
$$

